May 2004 • NREL/TP-500-36238

\title{
International Energy Agency Wind Turbine Round-Robin Test Task
}

\section{Final Report}

\author{
H.F. Link and R. Santos
}

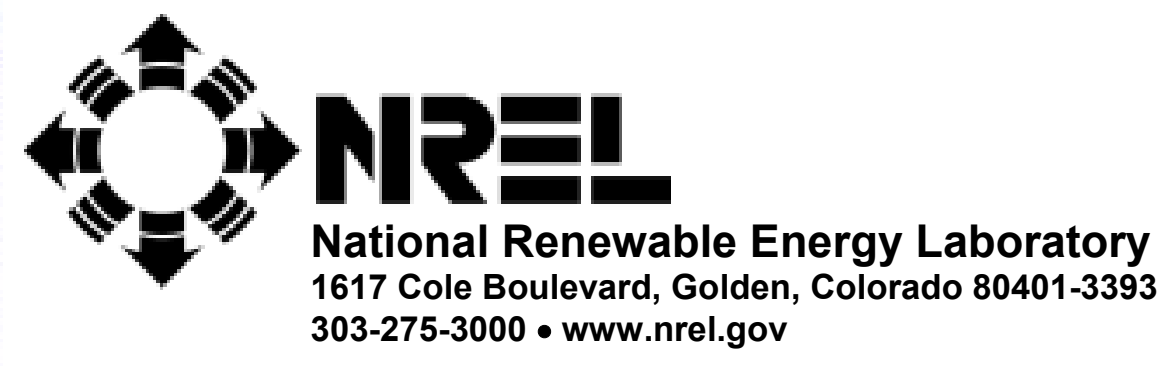

Operated for the U.S. Department of Energy

Office of Energy Efficiency and Renewable Energy

by Midwest Research Institute • Battelle

Contract No. DE-AC36-99-G010337 


\section{International Energy Agency Wind Turbine Round-Robin Test Task}

Final Report

\section{H.F. Link and R. Santos}

Prepared under Task No. WER4.3601

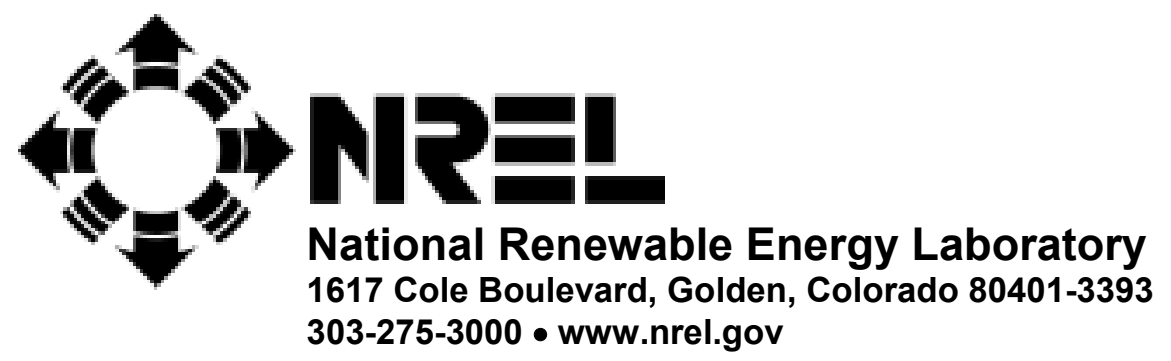

Operated for the U.S. Department of Energy Office of Energy Efficiency and Renewable Energy

by Midwest Research Institute • Battelle

Contract No. DE-AC36-99-G010337 


\section{NOTICE}

This report was prepared as an account of work sponsored by an agency of the United States government. Neither the United States government nor any agency thereof, nor any of their employees, makes any warranty, express or implied, or assumes any legal liability or responsibility for the accuracy, completeness, or usefulness of any information, apparatus, product, or process disclosed, or represents that its use would not infringe privately owned rights. Reference herein to any specific commercial product, process, or service by trade name, trademark, manufacturer, or otherwise does not necessarily constitute or imply its endorsement, recommendation, or favoring by the United States government or any agency thereof. The views and opinions of authors expressed herein do not necessarily state or reflect those of the United States government or any agency thereof.

Available electronically at http://www.osti.gov/bridge

Available for a processing fee to U.S. Department of Energy and its contractors, in paper, from:

U.S. Department of Energy

Office of Scientific and Technical Information

P.O. Box 62

Oak Ridge, TN 37831-0062

phone: 865.576.8401

fax: 865.576.5728

email: mailto:reports@adonis.osti.gov

Available for sale to the public, in paper, from:

U.S. Department of Commerce

National Technical Information Service

5285 Port Royal Road

Springfield, VA 22161

phone: 800.553 .6847

fax: 703.605.6900

email: orders@ntis.fedworld.gov

online ordering: http://www.ntis.gov/ordering.htm 


\section{Forward}

This report summarizes the work performed under the auspices of the International Energy Agency's (IEA) Agreement for Cooperation in the Research and Development of Wind Turbine Systems (IEA R\&D WTS). The project was formalized as Annex XVI, Wind Turbine RoundRobin Test Task. Funding for this project was provided by a number of agencies. Principal among them was the U.S. Department of Energy's Wind Energy Program. This program is directed by the Office of Wind and Hydropower Technologies under the Assistant Secretary for Energy Efficiency and Renewable Energy. Participants wish to thank the U.S. Department of Energy (DOE) for their support in purchasing two of the three AOC 15/50 test turbines and in supporting the National Renewable Energy Laboratory (NREL) staff time and expenses for this project. Support was also provided by the Canadian, Danish, and Greek governments and the European Union. Participants also wish to thank the authorities in these governments for their support to purchase the third test turbine in Canada, and to ship, install and operate turbines in Canada, Denmark, and Greece.

The authors wish to express their deep appreciation for the contributions and support of other participants in this annex. Uwe Paulsen, from Risø in Denmark, coauthored the Test and Analysis plan, conducted all the turbine testing at Risø, helped develop methods for measuring pitch angle, and assisted in comparison of test results. Carl Brothers, from AWTS in Canada, conducted all turbine testing at AWTS. Fragiskos Mouzakis, from CRES in Greece, conducted the turbine testing at CRES, Kostas Papadopoulos, formerly from CRES and Nikos Stefanatos from CRES conducted the anemometer testing. Other contributors in time, energy, and support include Søren Linde, Troels Pedersen, and Peter Hjuler Jensen from Risø, Evangeles Morfiadakis and Apostolos Fragoulis formerly from CRES, Diego Prischich formerly from ANEA in Italy, Robert Sherwin, Bruce Johnson, Susan Childs all formerly at Atlantic Orient Corporation. And last but not least, we wish to acknowledge the originators of this task whose vision and guidance helped to keep us all on track, Sandy Butterfield at NREL and Dan Ancona formerly at the US DOE. 


\section{Contents}

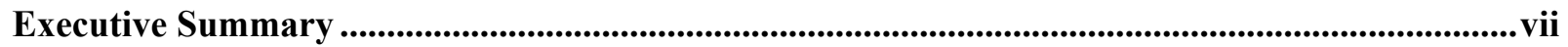

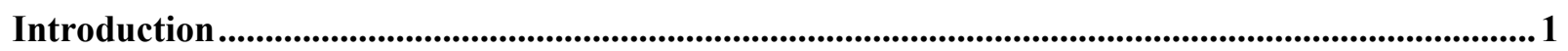

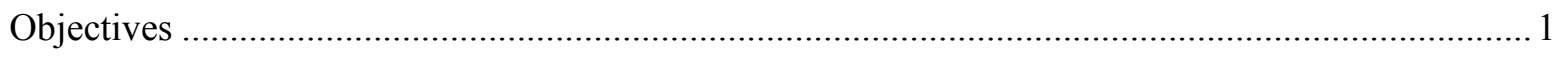

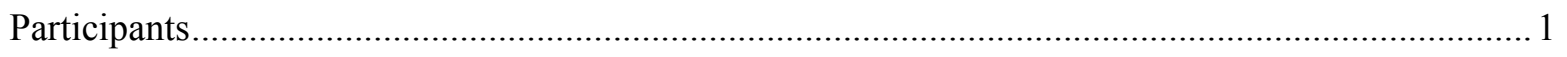

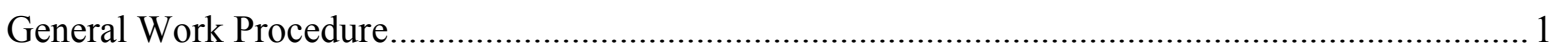

Subtask A: Development of Test and Analysis Plan .............................................. 1

Subtask B: Procurement and Installation of Test Turbines ........................................ 2

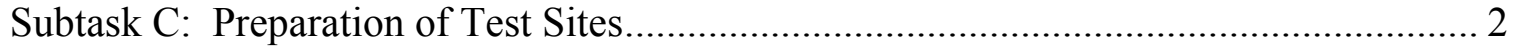

Subtask D: Testing of Standard Turbines and Data Analysis ...................................... 2

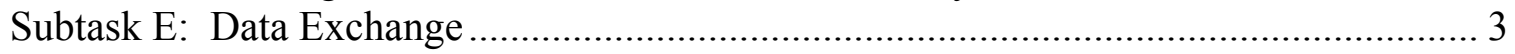

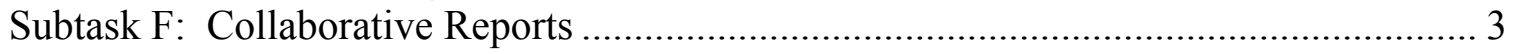

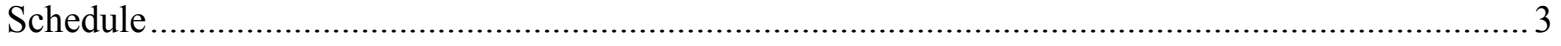

Description of AOC 15/50 Wind Turbines.....................................................................................................5

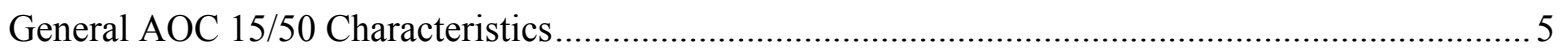

Turbine Configuration Differences Among AWTC, Risø, and NREL .......................................... 6

Description of Test Sites .................................................................................................................................. 7

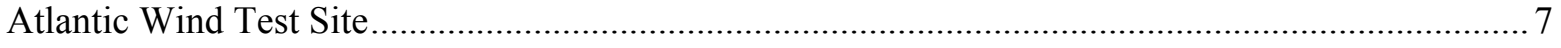

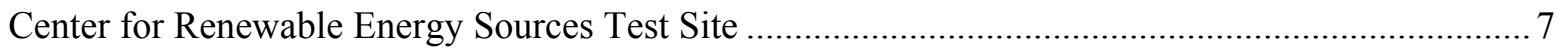

National Renewable Energy Laboratory Test Site ....................................................................... 7

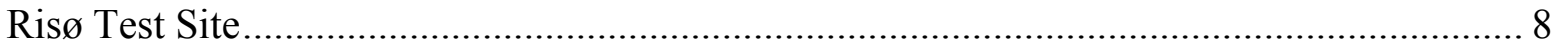

Results of Anemometer Comparisons .................................................................................................... 10

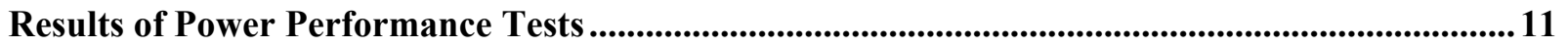

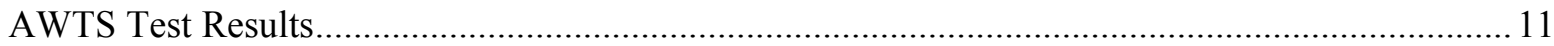

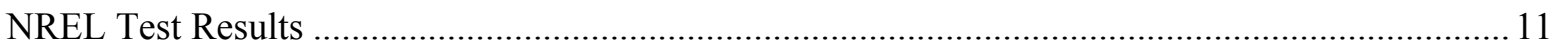

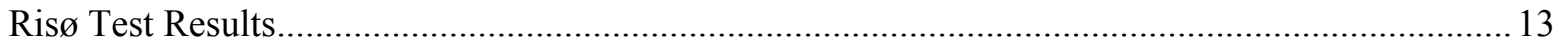

Comparison of Power Performance Test Results....................................................................... 14

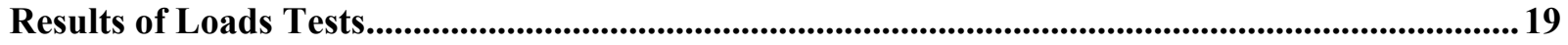

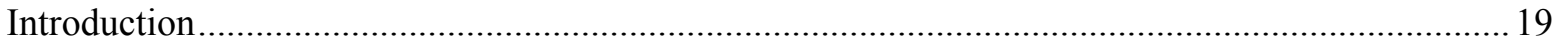

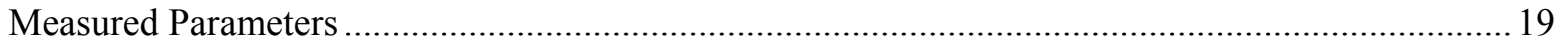

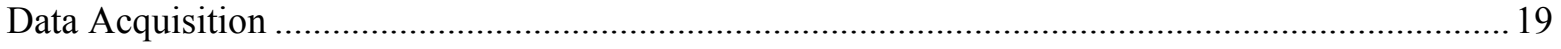

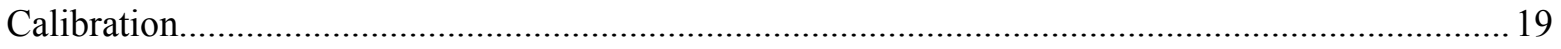

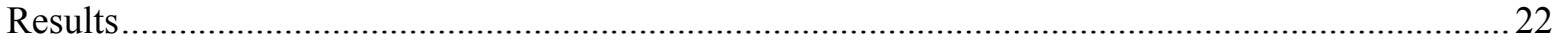




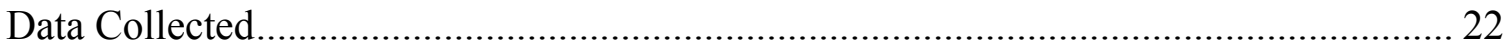

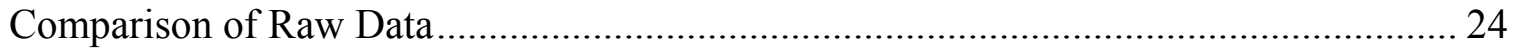

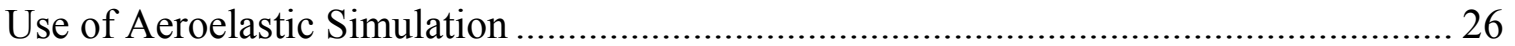

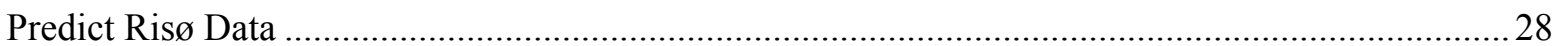

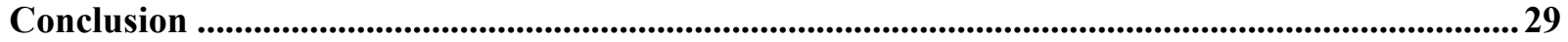

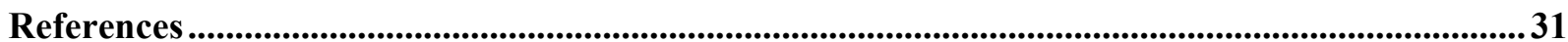




\section{Executive Summary}

This report describes the work and the results of Annex XVI, Wind Turbine Round-Robin Test Task, performed under the auspices of the International Energy Agency's (IEA's) Agreement for Cooperation in the Research and Development of Wind Turbine Systems (IEA R\&D WTS).

The objectives of Annex XVI were to validate wind turbine testing procedures, analyze and resolve sources of discrepancies, and to improve the testing methods and procedures. All participating laboratories tested similar wind turbines at their own facilities, using comparable test instrumentation and data acquisition equipment. The intent was to resolve discrepancies in the test data and to recommend improvements in testing procedures and calibration methods. This effort also contributes to meeting the requirements of proficiency testing as mandated by the IEC/ISO 17025, the quality standard for testing and calibration laboratories, and for mutual recognition of wind turbine certification capabilities.

In Annex XVI, four participating laboratories conducted tests on three different AOC 15/50 wind turbines. Power performance testing was completed by three of the laboratories and load testing was completed by two laboratories. Additional testing was completed on anemometers because these instruments are critical for comparable results. The participating laboratories were:

1. Atlantic Wind Test Site (AWTS), Prince Edward Island, Canada: AWTS completed a power performance test of the AOC 15/50 wind turbine

2. Center for Renewable Energy Sources (CRES), Pikermi, Attiki, Greece: CRES initiated loads and power performance testing of the AOC 15/50 wind turbine. CRES also performed extensive anemometer comparison testing.

3. National Renewable Energy Laboratory (NREL), Golden, Colorado, U.S.A.: NREL completed loads and power performance testing of the AOC 15/50 wind turbine. In addition NREL was the operating agent for Annex XVI.

4. Risø National Laboratory (Risø), Roskilde, Denmark: Risø completed power performance and loads testing of the AOC 15/50 wind turbine.

Salient findings of the study were as follows:

1. After wind tunnel calibrations, common cup anemometers demonstrate differences in readings obtained in complex terrain up to $2 \%$.

2. The response of common anemometers to tilt angle varies from -4 to $+4 \%$ depending upon anemometer type and whether the anemometer is angled toward the wind or away from the wind.

3. IEC 61400-12 requirements for rejection of test data may lead to large variations in test results depending upon how the testing organization defines "turbine availability." In some cases, data may be rejected because the turbine is off-line in what is otherwise normal operation. The new draft of IEC 61400-12 specifies that off-line data shall NOT be rejected when the turbine is otherwise operating normally.

4. Test results can be strongly influenced by other interpretations of IEC 61400-12 wherein conditions such as up-wind operation, tip brake deployment or non-operation due to brake cooling are interpreted as "normal" or "faulted" by the testing organization.

5. Measurement of blade pitch settings is more difficult and uncertain than previously assumed by participants.

6. Differences in turbine setup and test site conditions prevents direct comparison of loads results.

7. Models can be tuned only if data are available from a sufficient wind speed range to define alpha from the linear region through stall. 
8. If sufficient data are available to properly tune a model, it can be used to predict loads data obtained under quite different turbine and test conditions. Therefore the model can be used to estimate loads under all of the IEC load cases. 


\section{Introduction}

International recommended practices and standards for testing wind turbines are being developed by Technical Committee 88 of the International Electrotechnical Commission (IEC) and other agencies. As countries adopt these new standards, a mechanism should be in place to ensure that turbines are certified to common criteria. Common criteria could enable different countries to accept foreign certifications in lieu of their own. However, countries have found that there can be discrepancies between tests conducted in different locations using different test equipment. A round-robin test of anemometers demonstrated that even simple wind speed measurements can be significantly affected by different anemometer calibration procedures. Power curve, noise, and load tests of full turbines for certification programs in different countries may reveal important differences. A basis for exchanging test reports should be established to demonstrate that these tests can be reliably conducted in different locations by different testing agencies and achieve similar results. Results from this demonstration would facilitate international certification harmonization efforts.

A series of round-robin comparison tests at participating national laboratories and other interested test stations was suggested as a means of validating test procedures and establishing reciprocity between different certification testing laboratories. Participating laboratories were to use test methods as described in the IEC standards. Thelaboratories were to test identical machines, using comparable test instrumentation and data acquisition equipment. Laboratories planned to resolve discrepancies in the test data and identify improvements in testing procedures and calibration methods. This effort could also serve as justification for mutual recognition of foreign certifications.

\section{Objectives}

The objectives of this task are to validate wind turbine testing procedures, analyze and resolve sources of discrepancies, and improve the testing methods and procedures.

\section{Participants}

1. Risø Test Station for Wind Turbines, Denmark

2. Italian Agency for New Technology, Energy and the Environment, (ENEA) Italy

3. Center for Renewable Energy Sources (CRES), Greece

4. Atlantic Wind Test Site, Canada

5. National Renewable Energy Laboratory (NREL), United States of America

NREL was the operating agent for Annex XVI.

\section{General Work Procedure}

The following subtasks were identified in the work statement for Annex XVI:

\section{Subtask A: Development of Test and Analysis Plan}

The first stage of the Annex was to define the major activities in a joint test and data analysis plan. This plan specified testing techniques, instrumentation, calibration procedures, test matrices, data analysis procedures, reporting requirements and collaborative meetings. This document was drafted and received general approval from the participants. It was not published. 


\section{Subtask B: Procurement and Installation of Test Turbines}

The objective of this subtask was to provide identical turbines for testing. The operating agent (OA) provided two turbines for testing. One was installed at the National Wind Technology Center in Colorado, U.S.A. One was sent to Risø and later to CRES for testing. AWTS tested their own turbine.

Participants in the Annex selected Atlantic Orient Corporation's AOC 15/50 as the standard test turbine. It is fixed-pitch, stall-regulated, three-bladed, down-wind, and free-yaw turbine with a 15-meter diameter rotor and rated at $50 \mathrm{~kW}$. This turbine was selected primarily because it offered an attractive compromise between the consistency in performance typical of large turbines and the relative ease and low cost of small turbines. It was intended that the turbines be built to tight tolerances to ensure comparability of test results. However a variety of factors contributed to variations in the three turbines. In particular, the European turbine operated on a 50-Hz grid and, even with alternate gearing, had slightly different rotor speed than the U.S. and Canadian turbines operating on a $60-\mathrm{Hz}$ grid.

The OA's 50-Hz turbine was made available sequentially to Risø and CRES. Shipping of the OA's turbine to the each participant's site was to be the responsibility of that participant. However, as the Annex was conducted this arrangement was changed so that participants paid to ship the turbine to the next test site. Therefore, CRES is responsible for shipping costs to return the turbine to the United States. Commissioning, normal maintenance, and decommissioning were the responsibility of the participant responsible for the site. The OA retained ownership of the turbine and it could be recalled at the OA's discretion if reasonable progress is not being made towards the project schedule. In this event, a reasonable return date would be negotiated with the current participant. The OA bears no liability for any damages caused by the turbine to property or people during this program.

Normal maintenance and repairs of the turbine were the responsibility of the participant. The manufacturer was available to consult with the participant and supply parts for this maintenance as needed. If major repairs were needed, they were paid for at the sole discretion of the OA.

Atlantic Orient Corporation provided documentation (drawings, schematics, etc.) of the turbine to the OA. The OA provided basic documentation of the turbine (manuals, etc.) to the participants. No additional documentation was distributed.

\section{Subtask C: Preparation of Test Sites}

Each participant operating a test site prepared that site for testing. These preparations include provision of utility power and an adequate foundation for the test turbine and provision of a suitable meteorological tower. The participant operating a test site conducted safety system checkout tests in accordance with its own procedures and those recommended by the turbine manufacturer. All participants installed and calibrated their own instrumentation and data acquisition equipment according to the test plans.

\section{Subtask D: Testing of Standard Turbines and Data Analysis}

The objective of this subtask was to obtain test reports for later comparison of results. Each participant was to conduct and report on the following tests:

$\begin{array}{ll}\circ & \text { Anemometer exchange and calibration (similar to EU exchange) } \\ \circ & \text { Noise measurement test } \\ \circ & \text { Power performance test } \\ \circ & \text { Loads test } \\ \circ & \text { Safety system checkout test }\end{array}$

After initial planning of this Annex, participants decided to limit anemometer characterization to a study performed at CRES and described below. Noise tests were eliminated. Safety and function tests were 
performed at NREL and Risø but the results were not compared. Power performance testing was begun at all four test sites. However only AWTS, Risø, and NREL completed both the site calibration phase of power performance testing and the power performance test itself. Only Risø and NREL completed loads testing.

\section{Subtask E: Data Exchange}

The objective this subtask was to assess the comparability of test results and to determine cause for differences in results as appropriate. Participants exchanged test reports from the tests conducted in Subtask D. Raw data may be exchanged as required to resolve differences in results.

\section{Subtask F: Collaborative Reports}

The objective of this subtask is to document the findings of this task. The participants originally planned to write a report on each of the comparison tests. Later, participants decided to report the results of anemometer characterizations as one report and combine the findings of power performance and loads test comparisons in this Annex summary report.

\section{Schedule}

The Annex was approved in October 1995. The original completion time was October 1997. However, occurrences delayed completion until October 2003 including:

- Delay in delivery and preparation of the $50-\mathrm{Hz}$ wind turbine

- Delay in completion of testing at CRES

- Delay in completion of results comparisons and final report

Figure 1 shows the final schedule for the Annex. 


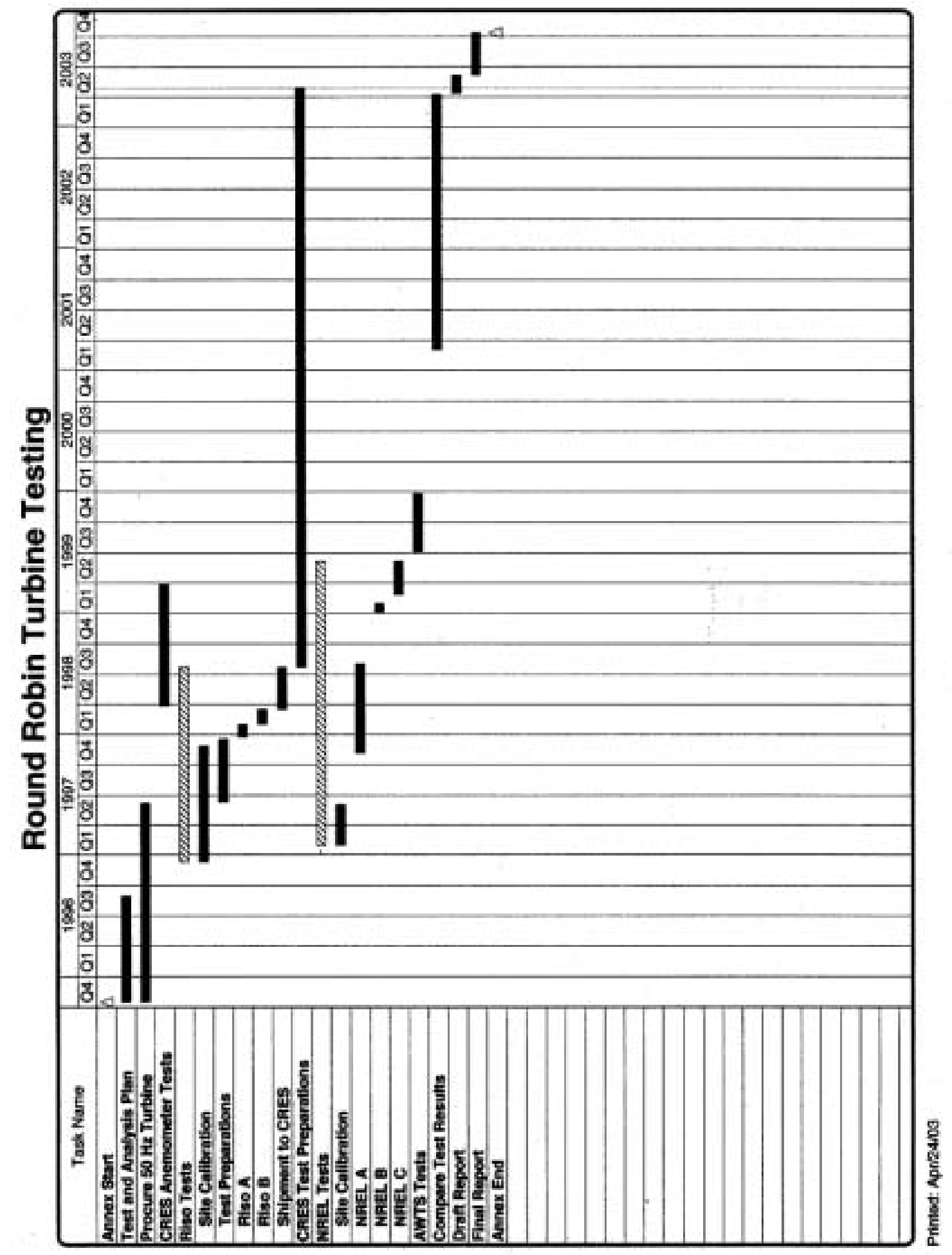

Figure 1. Schedule of IEA annex XVI, round-robin turbine test. 


\section{Description of AOC 15/50 Wind Turbines}

\section{General AOC 15/50 Characteristics}

The AOC 15/50 wind turbine is a relatively simple design and, because of its smaller size, it is easier and less expensive for the participant to transport and install than today's modern, utility grade turbines. The turbine is a three-bladed downwind, free-yaw, constant-speed, stall-regulated machine. The drivetrain, including gearbox, generator, and parking brake, is not covered by a nacelle.

The blades are wood-epoxy construction using SERI airfoils that are $7.2 \mathrm{~m}$ long, and, when mounted on the hub, combine to make a rotor with a diameter of $15 \mathrm{~m}$. The primary braking system consists of tip brakes that are latched using electromagnets and released on normal and emergency shutdowns. A secondary brake system is electrodynamic - wherein the generator is disconnected from the grid and connected to a resistor/capacitor bank. Finally, after the aerodynamic and electrodynamic brakes slow the rotor to idle, a spring-loaded, electromagnetically-released parking brake stops and holds the rotor for parking.

Power and rotational speed for the $50-$ and $60-\mathrm{Hz}$ turbines differ because of the torque limitation of the generator and the necessity for integral number of teeth in each of the gear sets. At $60 \mathrm{~Hz}$ and 480 volts, the generator spins at $1800 \mathrm{rpm}$ and can produce a maximum continuous power of $65 \mathrm{~kW}$. At $50 \mathrm{~Hz}$ and 400 volts, the generator spins at $1500 \mathrm{rpm}$ and must be derated to a maximum continuous power of 55 $\mathrm{kW}$. Different gearbox ratios nullify most of the difference in generator speed, but the $60-\mathrm{Hz}$ turbine spins slightly faster at $65 \mathrm{rpm}$ compared to the 50-Hz turbine's $62 \mathrm{rpm}$. Finally, AOC specified a $1.54^{\circ}$ pitch setting at the tip for the $60-\mathrm{Hz}$ turbine. This setting results in stall at a higher wind speed and higher maximum power than the $50-\mathrm{Hz}$ turbine's specified pitch of $0.90^{\circ}$. In practice, it is difficult to determine pitch to within $0.1^{\circ}$ so subsequent discussions of pitch setting, measurements are expressed to the closest tenth of a degree.

The tower is a three-legged lattice steel structure that is $24.4 \mathrm{~m}$ high with a $25 \mathrm{~m}$ hub height. The machine is controlled by the Koyo DirectLogic 205 PLC controller. Table 1 lists configuration and operational data for the AOC 15/50.

Table 1. Test Turbine Configuration and Operational Data

\begin{tabular}{|c|c|c|}
\hline Manufacturer & \multicolumn{2}{|c|}{ Atlantic Orient Corporation } \\
\hline Model & \multicolumn{2}{|c|}{ AOC $15 / 50$} \\
\hline Rotation Axis & \multicolumn{2}{|c|}{ Horizontal } \\
\hline Orientation & \multicolumn{2}{|c|}{ Downwind } \\
\hline Number of Blades & \multicolumn{2}{|c|}{3} \\
\hline Rotor Hub Type & \multicolumn{2}{|c|}{ Rigid } \\
\hline Rotor Diameter $(\mathrm{m})$ & \multicolumn{2}{|c|}{15} \\
\hline Hub Height (m) & \multicolumn{2}{|c|}{25} \\
\hline Performance & 60-Hz model & 50-Hz model \\
\hline Rated Electrical Power $(\mathrm{kW})$ & 65 & 55 \\
\hline Rated Wind Speed $(\mathrm{m} / \mathrm{s})$ & 11.0 & 12.0 \\
\hline Cut-in Wind Speed $(\mathrm{m} / \mathrm{s})$ & 3.7 & 3.8 \\
\hline Cut-out Wind Speed $(\mathrm{m} / \mathrm{s})$ & 25 & 25 \\
\hline Peak Survival Wind Speed $(\mathrm{m} / \mathrm{s})$ & 59.5 & 59.5 \\
\hline
\end{tabular}




\begin{tabular}{|c|c|c|}
\hline \multicolumn{2}{|l|}{ Rotor } & \multirow[b]{2}{*}{177} \\
\hline Swept Area $\left(\mathrm{m}^{2}\right)$ & 177 & \\
\hline On-line Rotational Speed (rpm) & 65 & 62 \\
\hline Coning Angle (deg) & 6 & 6 \\
\hline Tilt Angle (deg) & 0 & 0 \\
\hline Blade Pitch Angle, specified (deg) & $1.54^{\circ}$ & $0.9^{\circ}$ \\
\hline Power Regulation & \multicolumn{2}{|c|}{ Stall regulation } \\
\hline Over speed Control & \multicolumn{2}{|c|}{ Centrifugal deployment of tip brakes } \\
\hline \multicolumn{3}{|l|}{ Drive Train } \\
\hline Gearbox Manufacturer & \multicolumn{2}{|c|}{ Fairfield/AOC } \\
\hline Gearbox type & \multicolumn{2}{|c|}{ 2-stage planetary } \\
\hline Gear ratio & $1: 28.25$ & $1: 24.57$ \\
\hline Generator: Manufacturer & \multicolumn{2}{|c|}{ Magnatek } \\
\hline Generator Type & \multicolumn{2}{|c|}{ 3-phase induction } \\
\hline Generator Speed (rpm) & 1800 & 1500 \\
\hline Generator Voltage (volts AC) & 480 & 400 \\
\hline Generator Frequency $(\mathrm{Hz})$ & 60 & 50 \\
\hline \multicolumn{3}{|l|}{ Braking Systems } \\
\hline Aerodynamic Brake & \multicolumn{2}{|c|}{ Tip brakes on each blade } \\
\hline Electric Brake & \multicolumn{2}{|c|}{ Two-stage resistor/capacitor } \\
\hline Mechanical Brake & \multicolumn{2}{|c|}{ Generator-mounted, Sterns series 81,000} \\
\hline \multicolumn{3}{|l|}{ Yaw System } \\
\hline Wind Direction Sensor & \multicolumn{2}{|c|}{ None } \\
\hline Yaw Control Method & \multicolumn{2}{|c|}{ Free-yaw } \\
\hline \multicolumn{3}{|l|}{ Tower: } \\
\hline Type & \multicolumn{2}{|c|}{ Three-legged steel lattice } \\
\hline Height $(\mathrm{m})$ & \multicolumn{2}{|c|}{24.4} \\
\hline \multicolumn{3}{|l|}{ Control / Electrical System: } \\
\hline Controller: Make, Type & \multicolumn{2}{|c|}{ Koyo, DirectLogic 205} \\
\hline Power Converter: Make, Type & \multicolumn{2}{|c|}{ None } \\
\hline Output: Voltage, Frequency, Phases & $480 \mathrm{VAC}, 60 \mathrm{~Hz}, 3$-phase & $400 \mathrm{VAC}, 50 \mathrm{~Hz}, 3$-phase \\
\hline
\end{tabular}

\section{Turbine Configuration Differences Among AWTC, Risø, and NREL}

As noted in the table above, there are some significant differences between the 50 - and the $60-\mathrm{Hz}$ versions of the AOC 15/50. These differences are due primarily to the design limit of generator torque. To minimize the differences in performance that different rotor speeds and pitch angles would have on test results, participants attempted to configure each turbine as close as possible. A pitch setting of $0.9^{\circ}$ was selected as the primary configuration with the recognition that power output at $60-\mathrm{Hz}$ grid locations would be lower than normal for this turbine. Unfortunately, the turbine at AWTS was tested with a pitch setting of $-1.0^{\circ}$ to avoid operational problems that the turbine had been experiencing.

A second difference was rotor speed. With the limitations of compatible gear ratios, participants were unable to operate at identical rotor speeds. The NREL and AWTS turbines operated at $65 \mathrm{rpm}$ and the Risø turbine operated at $62 \mathrm{rpm}$ at rated power.

Finally, an unquantifiable difference was the blade profile. The blades tested in Europe and at the AWTS were manufactured by Gougeon Brothers, Inc., using the original mold. The blades tested at the NWTC 
were manufactured by Merrifield-Roberts, Inc., using a mold that was made from one of the Gougeon blades. It is not known how well the airfoil shapes were transferred to the second-generation blades.

\section{Description of Test Sites}

\section{Atlantic Wind Test Site}

The Atlantic Wind Test Site occupies 48 hectares on the northwest tip of Prince Edward Island, Canada. Most winds approach the test site from the Gulf of Saint Lawrence. The climate of eastern Canada provides a wide range of operating temperatures, frequent glaze icing events, and class five winds. The terrain rises to the west (prevailing wind direction), but a 10-meter cliff runs along the shore about 150 meters to the west of the turbine. Because of this cliff, the test site does not meet the requirements of IEC 61400-12.

The meteorological mast was positioned 2.3 rotor diameters on a bearing of $0^{\circ}$ with respect to magnetic north. The measurement sector was from $190^{\circ}$ to $20^{\circ}$.

AWTS conducted a site calibration test between December 1996 and February 1997. However, the test results were not made available to this project. Site calibration factors were not applied to wind speeds measured during the power performance test.

\section{Center for Renewable Energy Sources Test Site}

The CRES test site is located outside of Athens, Greece. The turbine is located on the upwind side of a ridge in complex terrain that does not meet the requirements of IEC 61400-12. CRES intended to perform a site calibration test after completing the power performance test. However, as of this report, testing of the turbine is not complete, and a site calibration has not been conducted.

\section{National Renewable Energy Laboratory Test Site}

NREL's AOC 15/50 wind turbine was located at Site 1.1 of the National Wind Technology Center, approximately $8 \mathrm{~km}$ south of Boulder, Colorado, U.S.A. The site is located in somewhat complex terrain at an approximate elevation of $1850 \mathrm{~m}$ above sea level. The meteorological mast is located 2.5 rotor diameters on a bearing of $292^{\circ}$ relative to true north. The measurement sector was from $255^{\circ}$ to $45^{\circ}$. The site assessment indicated that the site failed the requirements in IEC 61400-12 for terrain variations between $4 \mathrm{~L}$ and $8 \mathrm{~L}$, where $\mathrm{L}$ is the distance between the meteorological tower and the turbine.

NREL conducted a site calibration test between 21 January 1997 and 2 June 1997. The test indicated wind speed ratios (wind speed at the turbine position divided by wind speed at the meteorological tower) between 1.006 and 0.981 over the entire measurement sector. The result, less than $2 \%$ variation, shows that the site is effectively simple terrain suitable for good quality testing. The results of the NREL site calibration test were documented in a test report available to other participants in Annex XVI. Site calibration factors were applied to wind speeds measured during the power performance test. 


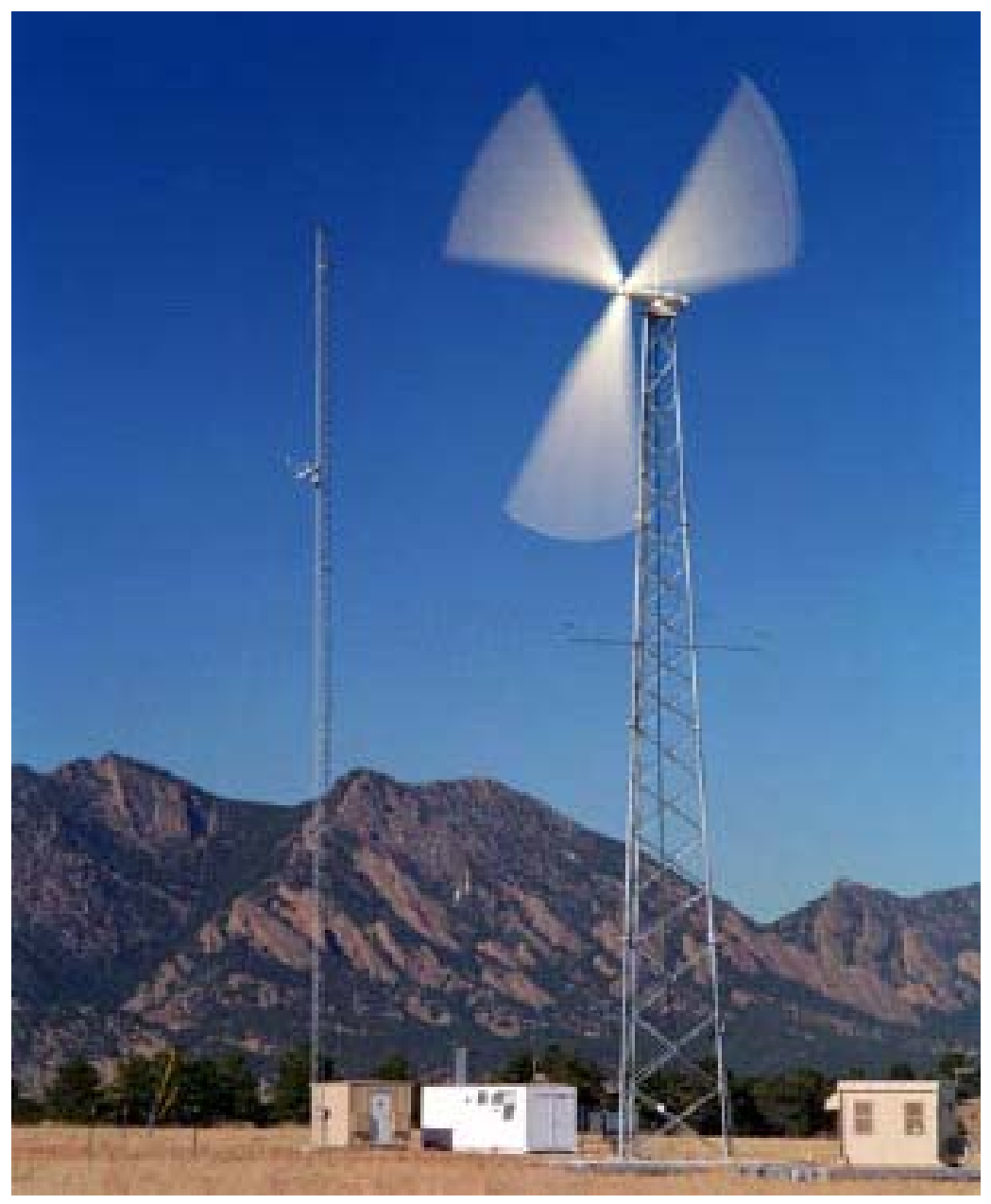

Figure 2. AOC 15/50 test turbine (left) at NREL.

\section{Risø Test Site}

The Risø test site was located at the Test Station for Wind Turbines, Risø National Laboratory, outside of Roskilde, Denmark. The site is fairly smooth with a slight slope to sea level toward the northwest. For historical reasons, the meteorological mast was positioned 4.2 rotor diameters on a bearing of $287^{\circ}$ with respect to magnetic north. This is an exception to IEC 61400-12 that requires the meteorological mast to be placed between 2 and 4 rotor diameters from the turbine. The measurement sector was from $222^{\circ}$ to $2^{\circ}$. The site assessment indicated that the site meets IEC $61400-12$ requirements for distances of $2 \mathrm{~L}$ and $4 \mathrm{~L}$ where $\mathrm{L}$ is the distance between the meteorological tower and the turbine. The site assessment did not evaluate the site at distances between $4 \mathrm{~L}$ and $8 \mathrm{~L}$.

A site calibration test was performed between 9 December 1996 and 30 November 1997, documented in the Risø report, Risø-I-1310(EN) and made available to other participants in Annex XVI. The test indicated wind speed ratios (wind speed at the turbine position divided by wind speed at the meteorological tower) between 1.005 and 0.982 for most of the measurement sector (from $222^{\circ}$ to $337^{\circ}$ ). This is within $2 \%$ as assumed as the maximum variation for a flat terrain site meeting the requirements of IEC 61400-12. However, for wind directions between $337^{\circ}$ and $2^{\circ}$, wind speed ratios decreased to as low as 0.955 or $4.5 \%$ - apparently because the wake of office buildings affected wind speed at the turbine. It is not known whether the site calibration factors were applied to wind speeds measured during the power performance test. 


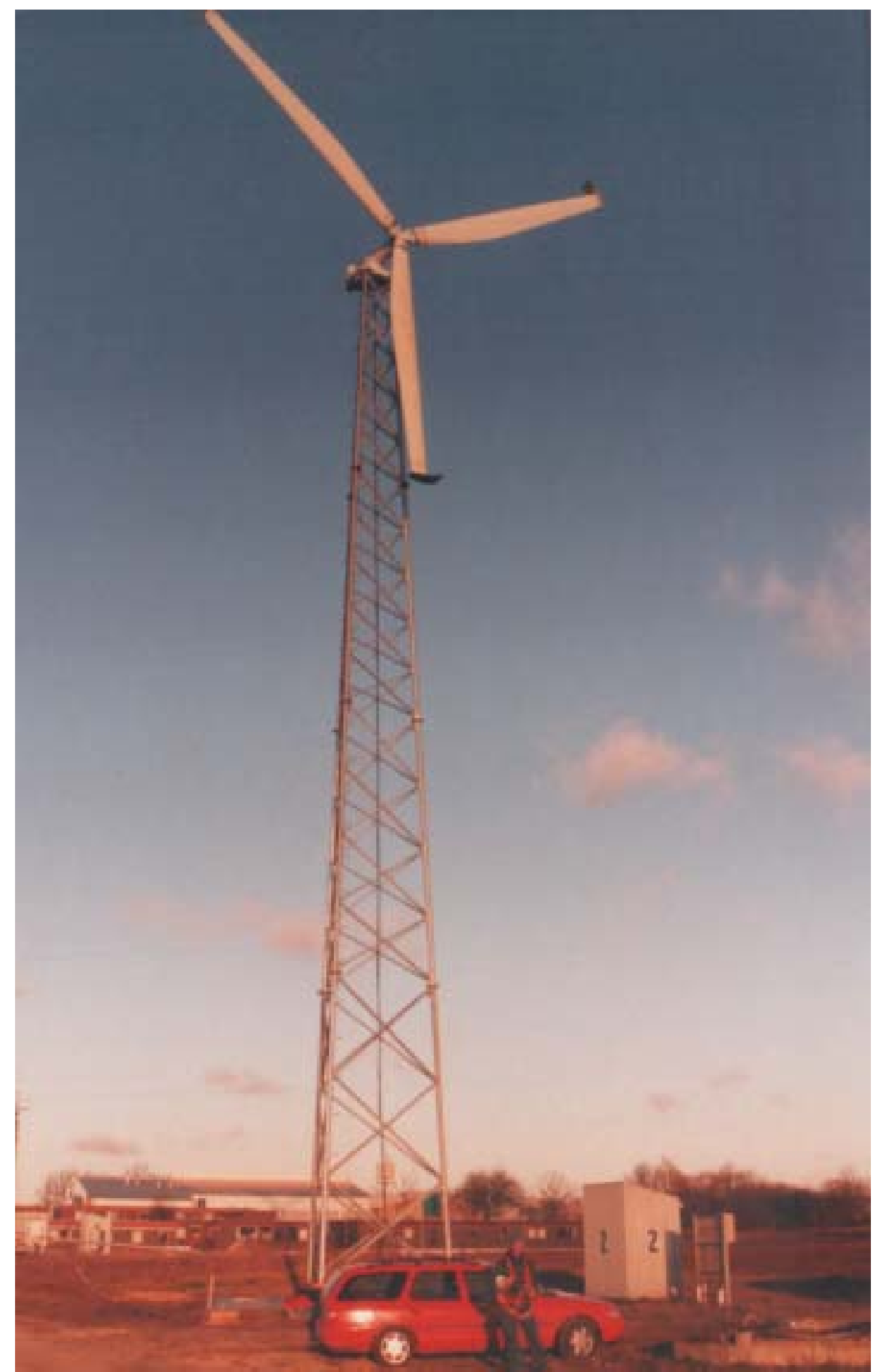

Figure 3. AOC 15/50 test turbine at Risø. 


\section{Results of Anemometer Comparisons}

Four anemometers were compared to a reference anemometer, a Vector A100K in a side-by-side field test. The anemometers were: Vector A100K (test anemometer), Climatronics F460, NRG Max\#40, and Met One 010C. CRES calibrated each anemometer at a local wind tunnel in accordance with MEASNET requirements (Stefanatos 1997). A 6m-long boom of rectangular cross-section (40x40mm) was mounted on a meteorological tower at $25.5 \mathrm{~m}$ above ground to support the reference anemometer and the anemometer under test. A hinged base at one end of the boom allows the anemometer under test to be rotated around the boom axis. The reference anemometer is installed on the permanent base at the other end of the boom. On both bases, the distance between the anemometer sensing volume and the boom exceeds the IEC-1400-12 requirements (IEC 1998).

Other instruments include a Vector W200P wind vane mounted on a boom at $23.8 \mathrm{~m}$, a second Vector W200P wind vane mounted at 24.1 with its axis horizontal to measure flow inclination, and a 3D ultrasonic anemometer at $20 \mathrm{~m}$ to characterize wind turbulence. The test site features a significant slope that affects winds from the south. In other directions the terrain is flat. Data were sampled at $1 \mathrm{~Hz}$ and processed into 1- and 10-minute averages.

Test results were:

1. Good correlations were obtained between 1-minute averaged wind speeds. In all cases correlation coefficients $\left(\mathrm{R}^{2}\right)$ were better than 0.9998 . In comparison, wind tunnel calibrations in steady flow under controlled conditions typically yielded correlation coefficients of 0.9999 .

2. Mounting effects for the test arrangement were small - less than $0.06 \mathrm{~m} / \mathrm{s}$ at $10 \mathrm{~m} / \mathrm{s}$ average wind speed.

3. Differences at $10 \mathrm{~m} / \mathrm{s}$ between the test anemometers and the reference Vector A100K anemometer were: $0.1 \%, 2.0 \%, 0.3 \%$, and $1.6 \%$ for a second Vector A $100 \mathrm{~K}$, a Climatronics F460, an NRG Max40, and a Met One 010, respectively. These differences depended on wind speed.

4. Differences in anemometer readings corresponded to distance constants of the instruments.

5. When tilted away from the wind (representing uphill flow), the Met One and Climatronics anemometers indicated higher than actual wind speed, the Vector indicated lower than actual wind speed, and the NRG indicated close to actual wind speed. The Vector could thus be characterized as measuring the horizontal component of wind speed while the NRG could be characterized as measuring the vector magnitude of wind speed.

6. When tilted toward the wind (representing downhill flow), all four anemometers indicated lower than actual wind speed.

This study was documented in a paper at the European Wind Energy Conference in 1999 (Papadopoulos, 1999). 


\section{Results of Power Performance Tests}

\section{AWTS Test Results}

AWTS reported a power curve as shown in Figure 4. They also reported that their turbine's pitch setting was $-1.0^{\circ}$. This pitch setting is quite conservative and, according to model predictions should limit maximum power to less than $50 \mathrm{~kW}$ on this $60-\mathrm{Hz}$ turbine. Maximum uncertainty was $2.3 \mathrm{~kW}$. Test results are much more consistent with model predictions and other tests if the pitch setting was actually $+1.0^{\circ}$. Also, the AWTS turbine's pitch setting was only measured by the position of the blade mounting bolts in the hub flange slots. Measurements obtained from CRES indicate that errors up to $2^{\circ}$ are possible because of variations in blade/hub geometry.

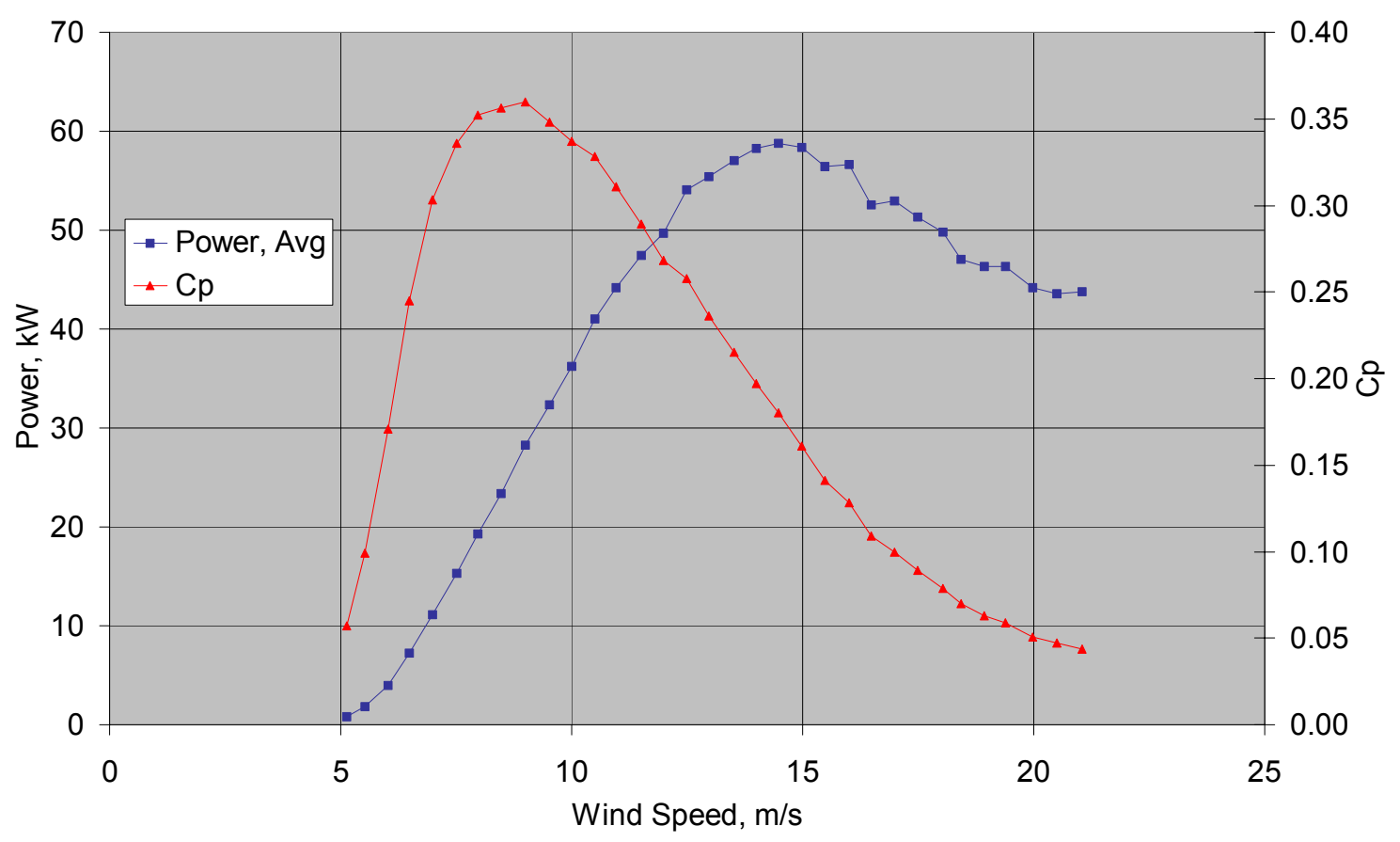

Figure 4. AWTS power performance test results.

\section{NREL Test Results}

NREL reported two power curves, one at a pitch setting of $1.5^{\circ}$ and one at a pitch setting of $0.9^{\circ}$. The first pitch setting is appropriate for a $60-\mathrm{Hz}$, AOC $15 / 50$ wine turbine installed at sea level. Given its location some $1860 \mathrm{~m}$ above sea level, the NREL test site has an average air density of about $1.0 \mathrm{~kg} / \mathrm{m}^{3}$. Thus a pitch setting of $1.5^{\circ}$ should result in maximum power approximately $81 \%$ of advertised or about $53 \mathrm{~kW}$. Power performance characteristics at site average air density for NREL are not comparable with results obtained at the other test sites. Therefore, NREL test results reported here are normalized to standard conditions of air density using the procedures in the IEC power performance standard.

NREL's first test for this project, "NREL B," was at a pitch setting of $1.5^{\circ}$ (See Figure 5). The maximum power for this test, normalized to standard conditions, was $65 \mathrm{~kW}$. Maximum uncertainty in winds 10.6 $\mathrm{m} / \mathrm{s}$ and below was $4.7 \mathrm{~kW}$. In higher winds, cut-out hysteresis and other effects push uncertainty as high as $37 \mathrm{~m} / \mathrm{s}$. 


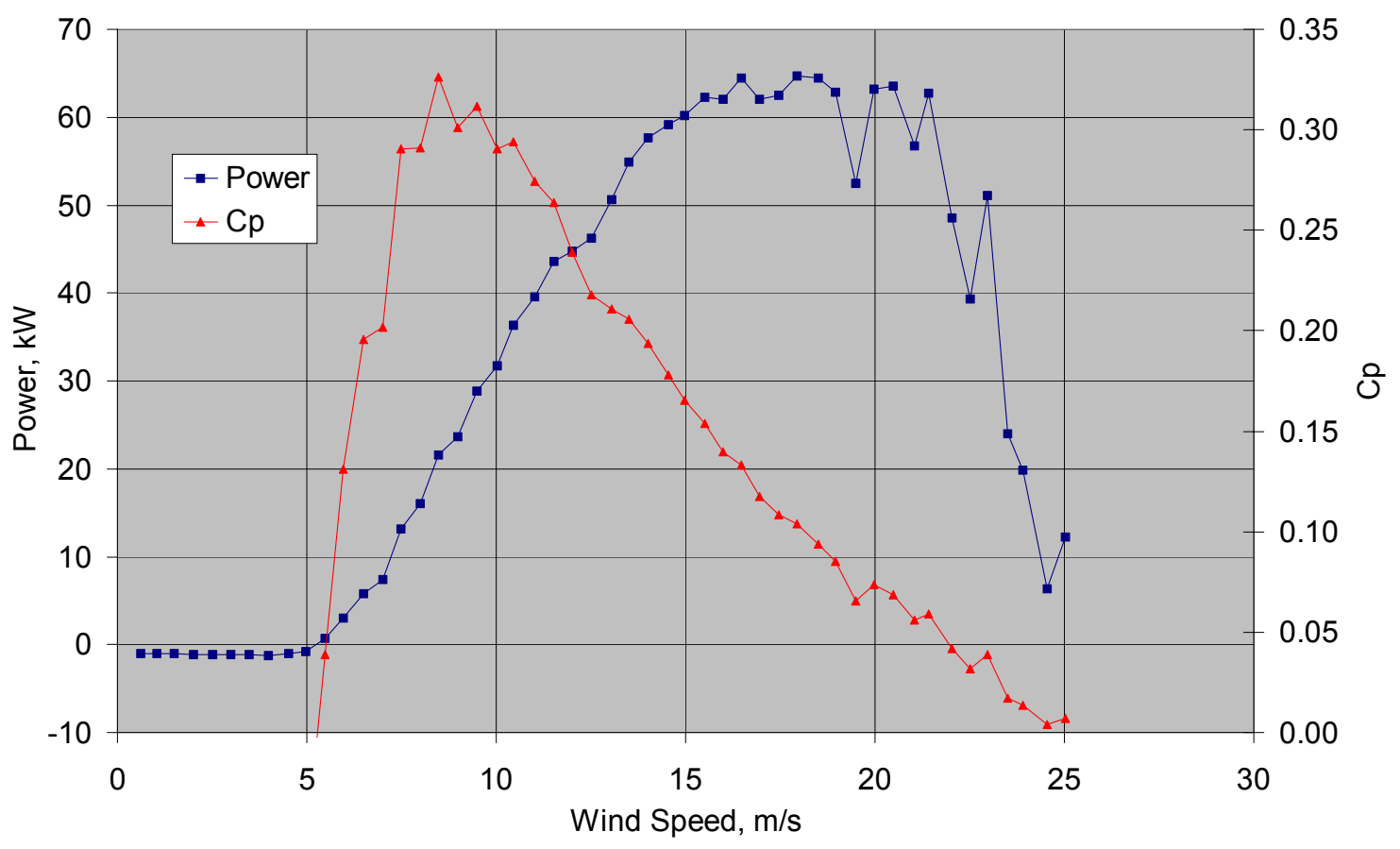

Figure 5. NREL power performance test results, pitch $=1.5$, all data.

NREL's second test, "NREL C," was conducted at a pitch setting of $0.9^{\circ}$ (See Figure 6). This test was conducted in the hope of matching the results obtained at Risø where tests were also to be conducted at a pitch setting of $0.9^{\circ}$. NREL reported a maximum normalized and bin-averaged power of $57 \mathrm{~kW}$ using all the valid data. Maximum uncertainty in this test was $7.1 \mathrm{~kW}$.

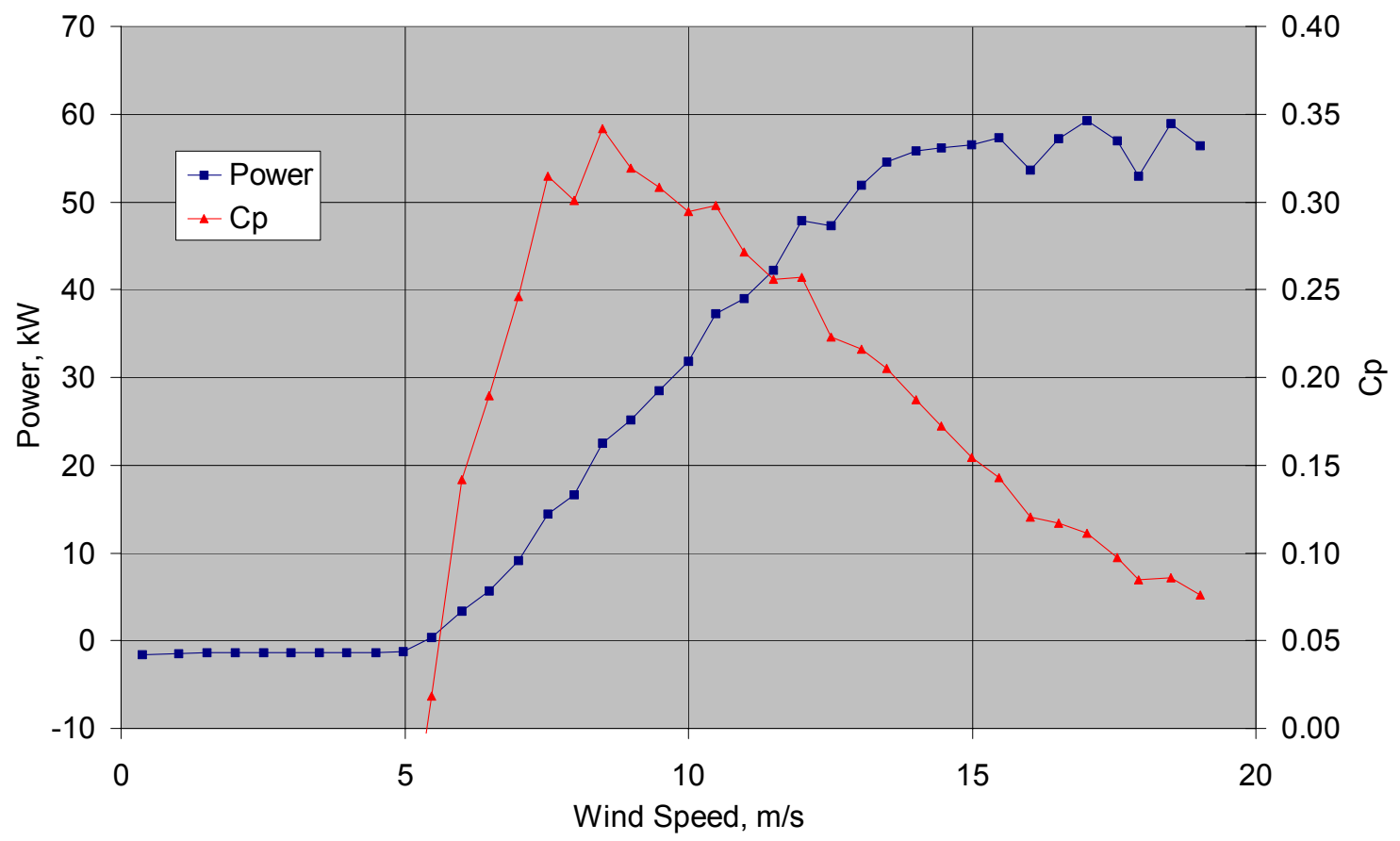

Figure 6. NREL power performance test results, pitch $=0.9$, all data. 


\section{Risø Test Results}

Risø reported two power curves corresponding with two pitch settings. The first pitch setting was intended to be at $0.9^{\circ}$, corresponding with the appropriate pitch setting for a $50-\mathrm{Hz}, \mathrm{AOC} 15 / 50$ wind turbine installed where the average air density is approximately $1.225 \mathrm{~kg} / \mathrm{m}^{3}$. However, after the test was completed, Ris $\varnothing$ and NREL staff noted that the pitch appeared to be different from $0.9^{\circ}$. Subsequent investigations indicated that the pitch for Ris $\varnothing^{\prime}$ s first test was most likely $-0.3^{\circ}$. For this test Risø A, maximum normalized and bin-averaged power was $54 \mathrm{~kW}$ as shown in Figure 7. Maximum $\mathrm{Cp}$ was $42 \%$, and maximum combined uncertainty was $3.7 \mathrm{~kW}$.

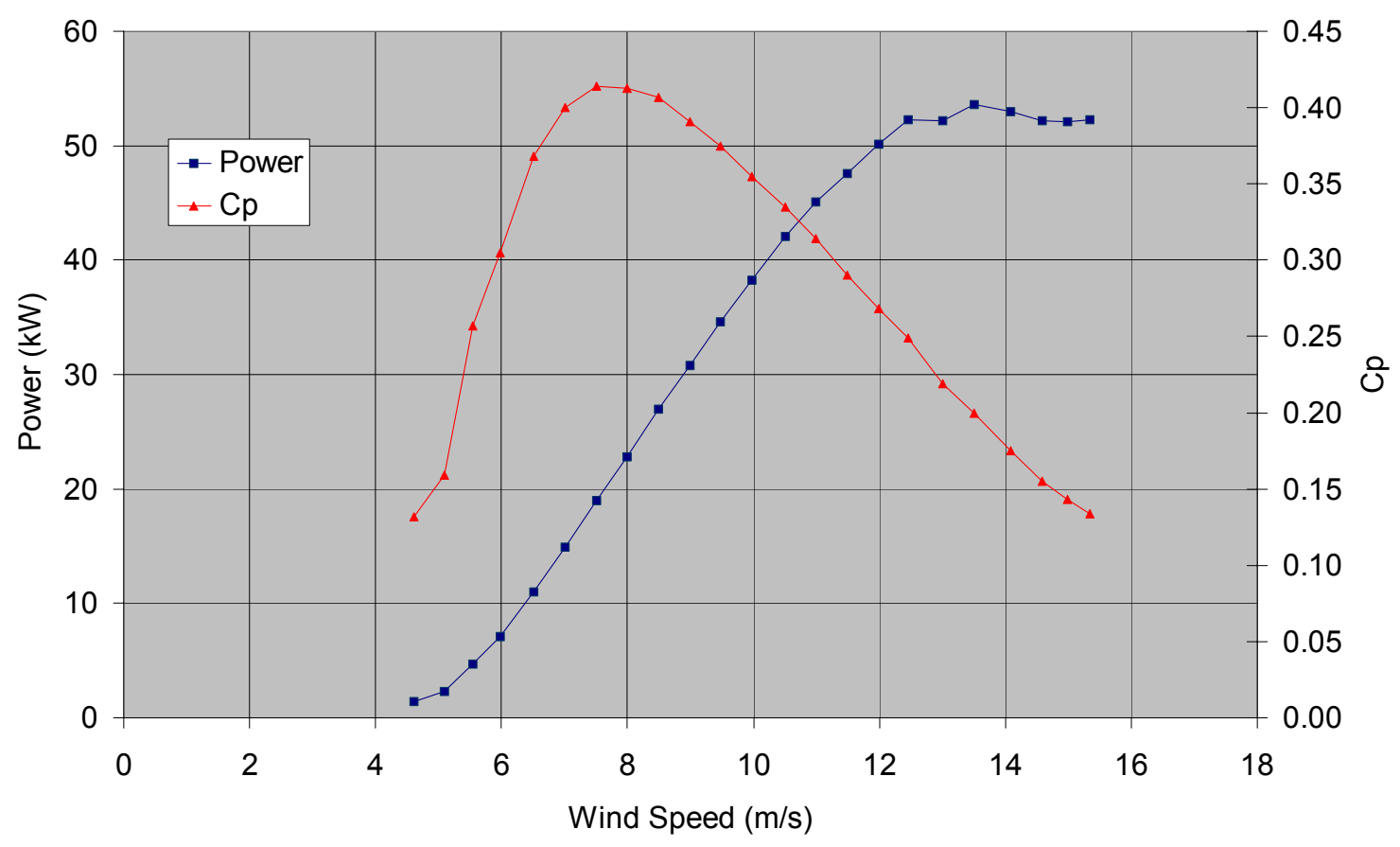

Figure 7. Risø power performance test results, pitch $=-0.3$.

Based on the best information available at the time, Risø staff repitched the turbine to obtain a setting of $0.9^{\circ}$. Later investigations indicated that the actual pitch setting for this test was $0.5^{\circ}$. For this measurement, an incomplete data set was obtained. Although insufficient high wind data were obtained to define maximum power, the power curve appears to be continuing upward past the highest measured point, $69 \mathrm{~kW}$ as shown in Figure 8. Peak Cp was 39\% and maximum combined uncertainty was $4.0 \mathrm{~kW}$. It is noteworthy that the data suggest that the turbine did not disengage from the grid at low winds. The power curve continues downward at wind speeds below cut in to a maximum power consumption of $6 \mathrm{~kW}$. 


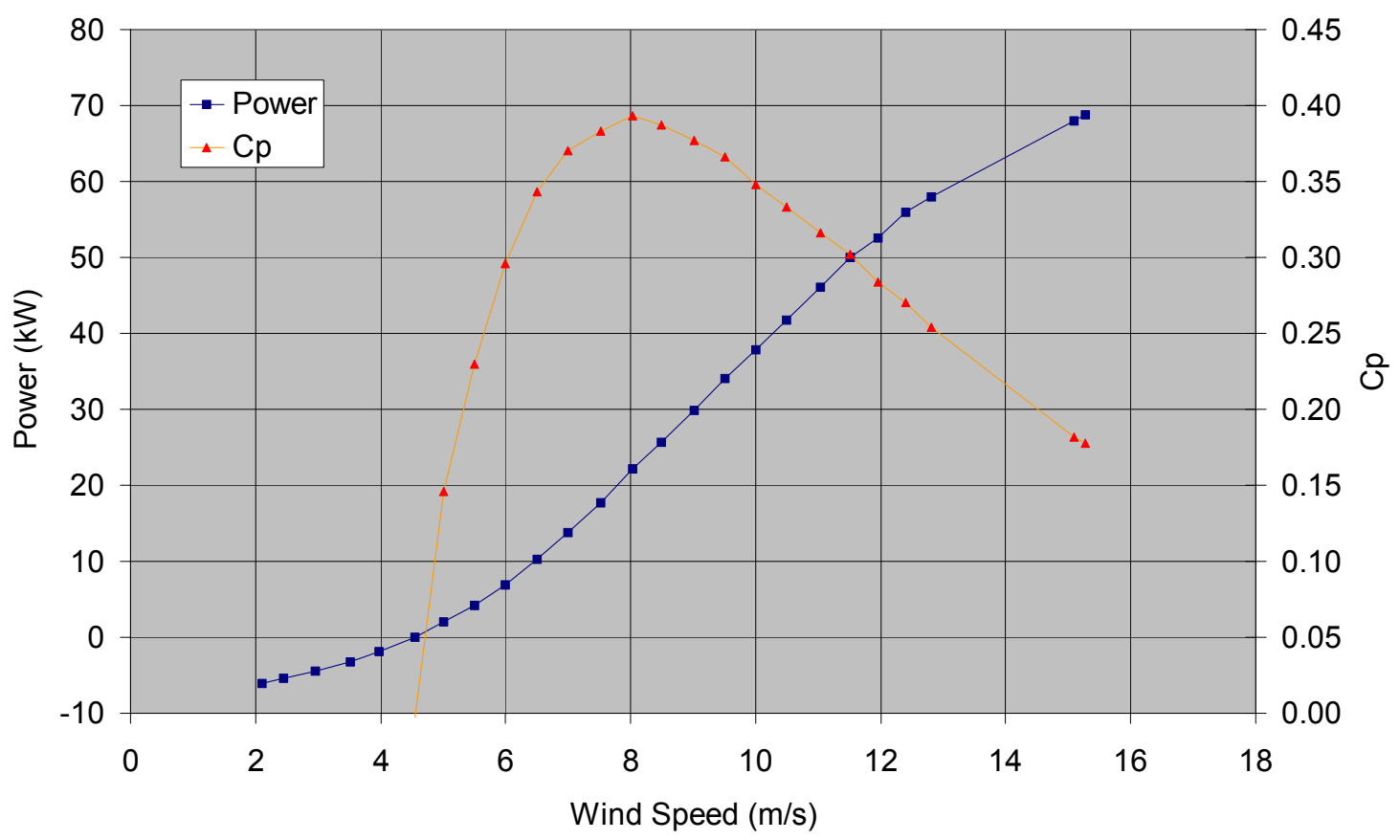

Figure 8. Risø power performance test results, pitch $=0.5$.

\section{Comparison of Power Performance Test Results}

Figure 9 shows the results of the power curves reported by participants using all valid data. It is apparent in Region II (between cut in and rated wind speed) that the NREL results are significantly lower than those of the other participants. This observation led to the first and most significant of several differences between tests - selection of data. 


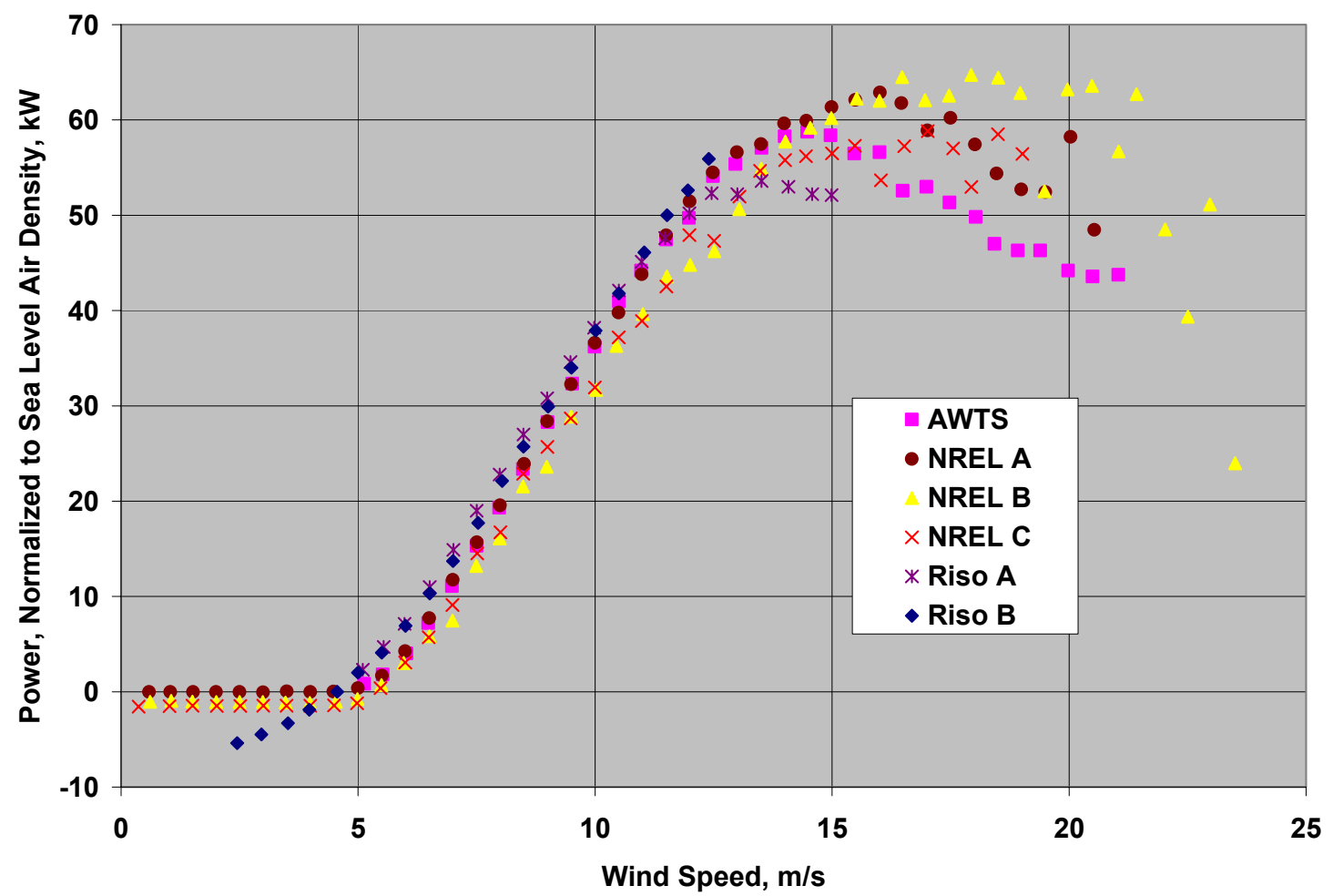

Figure 9. Power curves from all Participants using all valid data.

The IEC power performance standard specifies that data shall not be included in the power performance curve when the turbine is not operating normally. NREL had interpreted this requirement to mean that data obtained when the turbine is "unavailable" shall not be included. Risø and AWTS interpreted the requirement to mean that data obtained when the turbine is "not connected to the grid" shall not be included. In the case of the AOC 15/50 turbine, this difference in interpretation of the IEC standard causes a large impact on the comparability of test results. The AOC 15/50 turbine has a large cut-in hysteresis due to a 15-minute cool-down cycle for the dynamic brake resistors. In addition, the turbine may operate upwind a significant amount of time in highly turbulent winds. The vagueness of the IEC power performance standard permits these and other effects to be considered as "normal operation" because the turbine controller does not indicate a fault condition and no corrective action is required. Or they may be considered as "abnormal" operation and deleted from the power curve. This finding led directly efforts to revise and clarify the IEC standard.

To quantify this effect and to investigate the influence of other effects, NREL reanalyzed its power performance data. All data obtained when the turbine may have been in compromised state were removed from the data sets for both of the NREL tests. Figure 10 shows that the results from all the participants agree much better after this correction. 


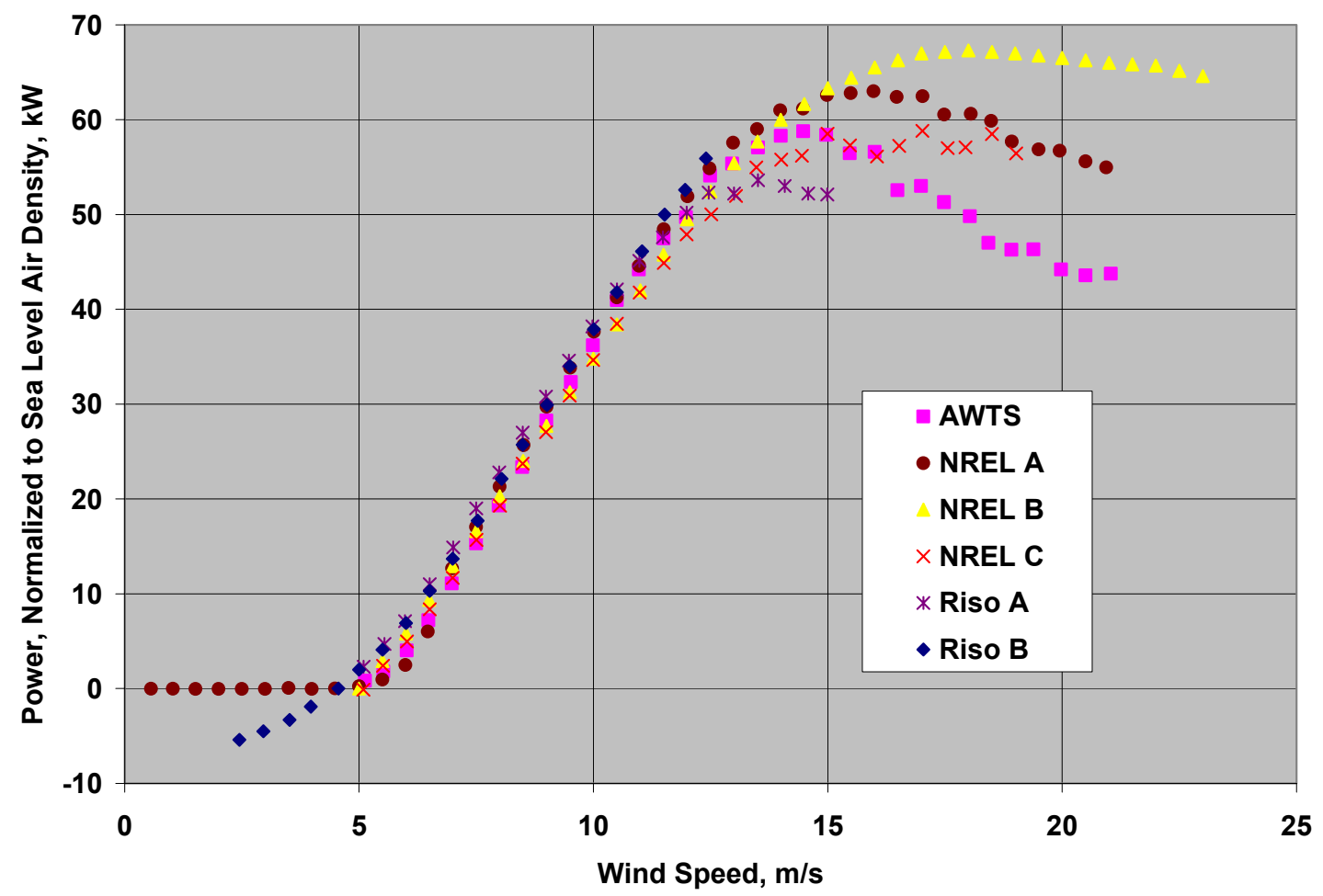

Figure 10. Power curves from all participants using "clean" data.

Other factors that are known to cause differences in power performance were investigated using a wind turbine dynamic simulation model, FAST. The FAST model accounts for the various pitch settings, the difference in rotor speed, and, to some extent, different turbulence levels at the test sites. Some inputs to the model, such as lift and drag coefficients and drivetrain efficiency, were adjusted to match NREL loads data. This adjustment led to good agreement between model predictions and NREL test results. Therefore, one should not use better agreement with model predictions as an indicator of superior test results.

First, we consider the NREL test results. Figure 11 shows that the test data agree reasonably well with FAST model predictions in low winds. However, as winds approach rated wind speed, both NREL tests indicate lower performance than predicted by the FAST model. 


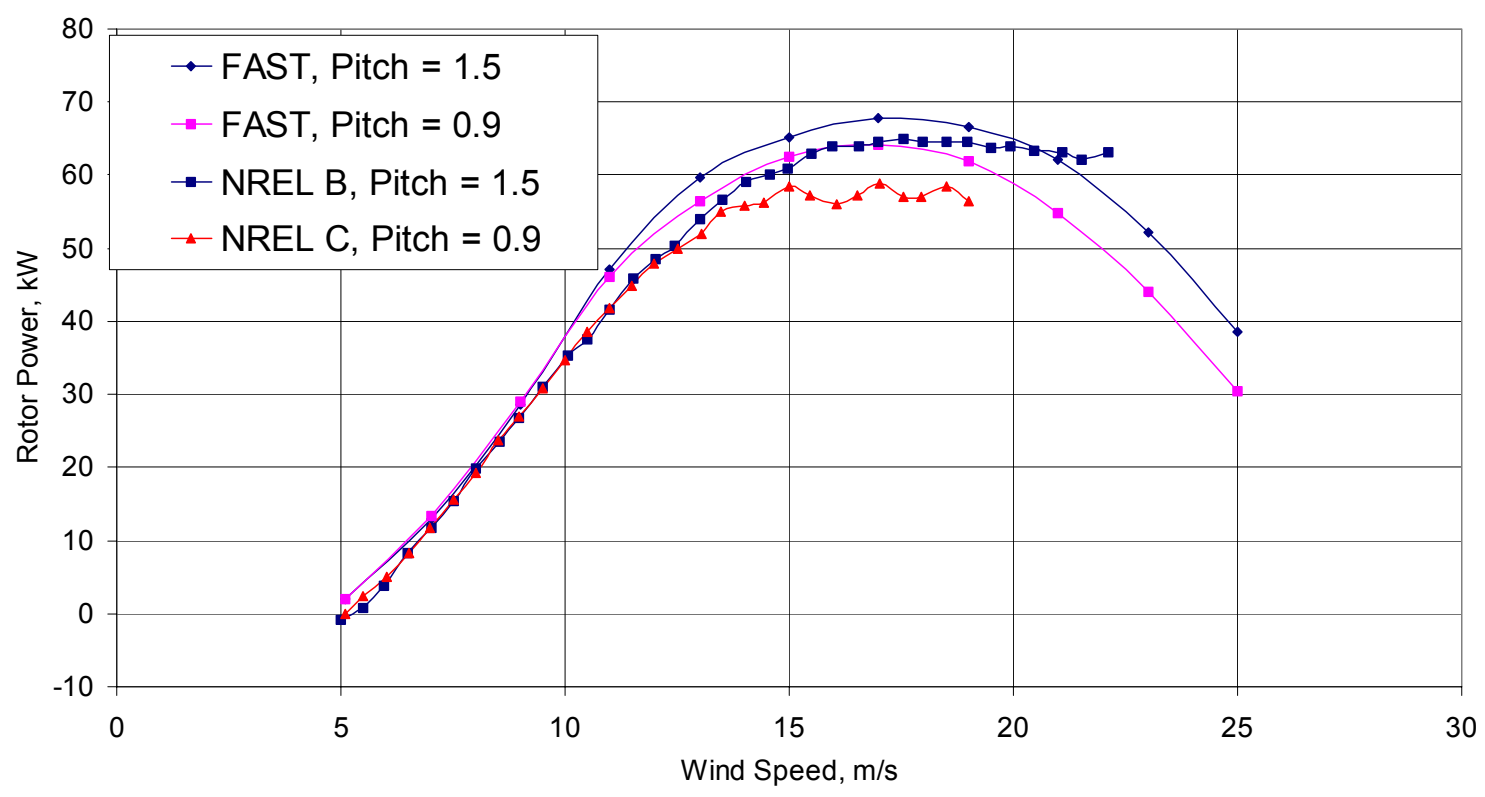

Figure 11. Comparison of FAST predictions with NREL test results.

AWTS test results agree reasonably well with FAST model predictions at low wind speeds as shown in Figure 12. At wind speeds between 10 and $15 \mathrm{~m} / \mathrm{s}$, the AWTS data correspond better with FAST predictions for a pitch setting of $0.9^{\circ}$ rather than the AWTS measured pitch setting of $-1.0^{\circ}$. However, test data indicate that the turbine reached peak power at about $15 \mathrm{~m} / \mathrm{s}-$ a value that agrees well with the FAST prediction for $-1.0^{\circ}$. There may be some error in the AWTS measurement of pitch angle as noted above.

Finally, Figure 13 compares the Risø test results with FAST model predictions for rotor speeds of $62 \mathrm{rpm}$ - the rotor speed of the 50-Hz turbine. As wind speed approaches rated power, the Risø test data diverge from the FAST model prediction with the Risø data indicating higher performance than predicted by FAST. 


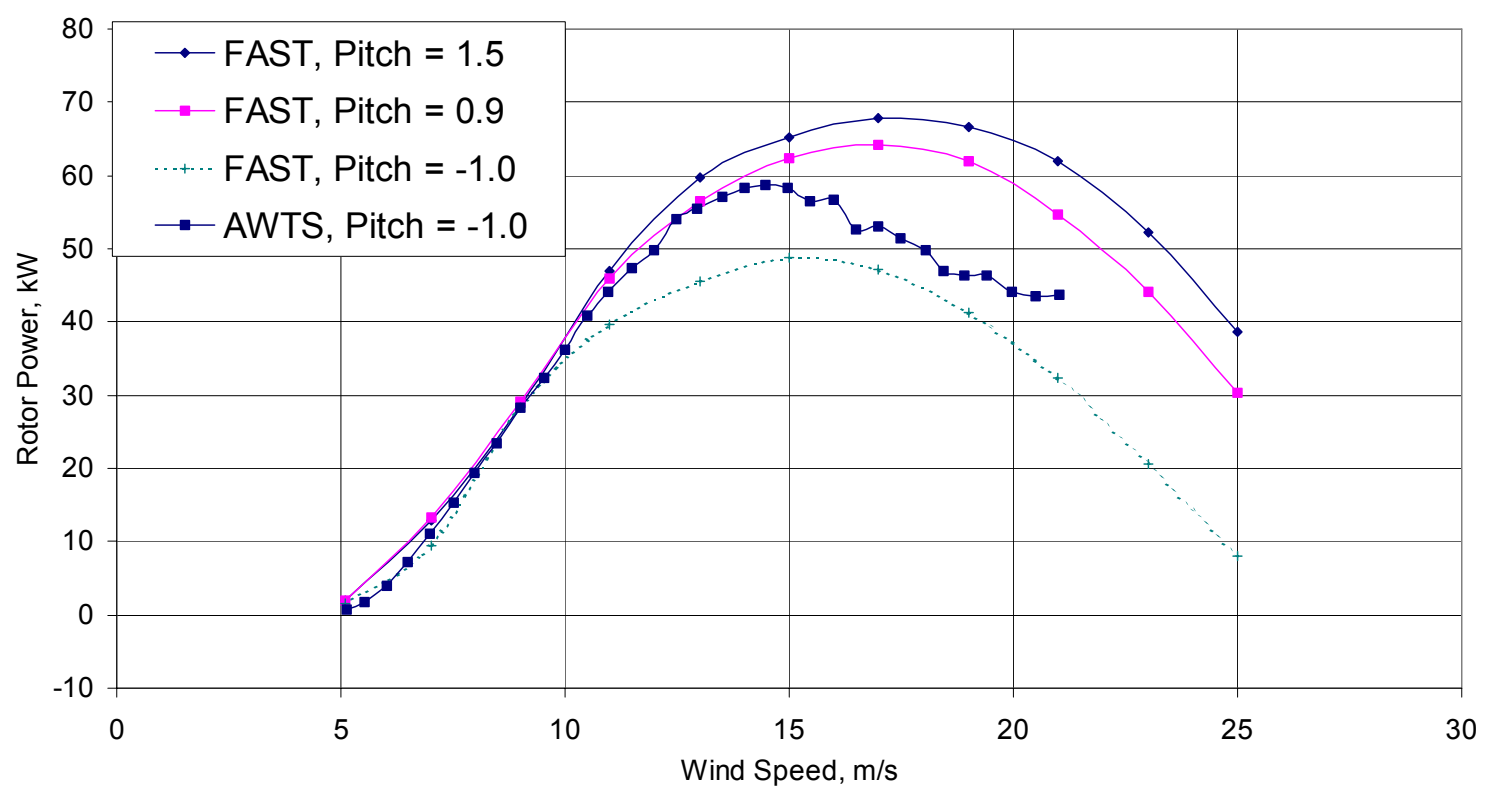

Figure 12. Comparison of FAST predictions with AWTS test results.

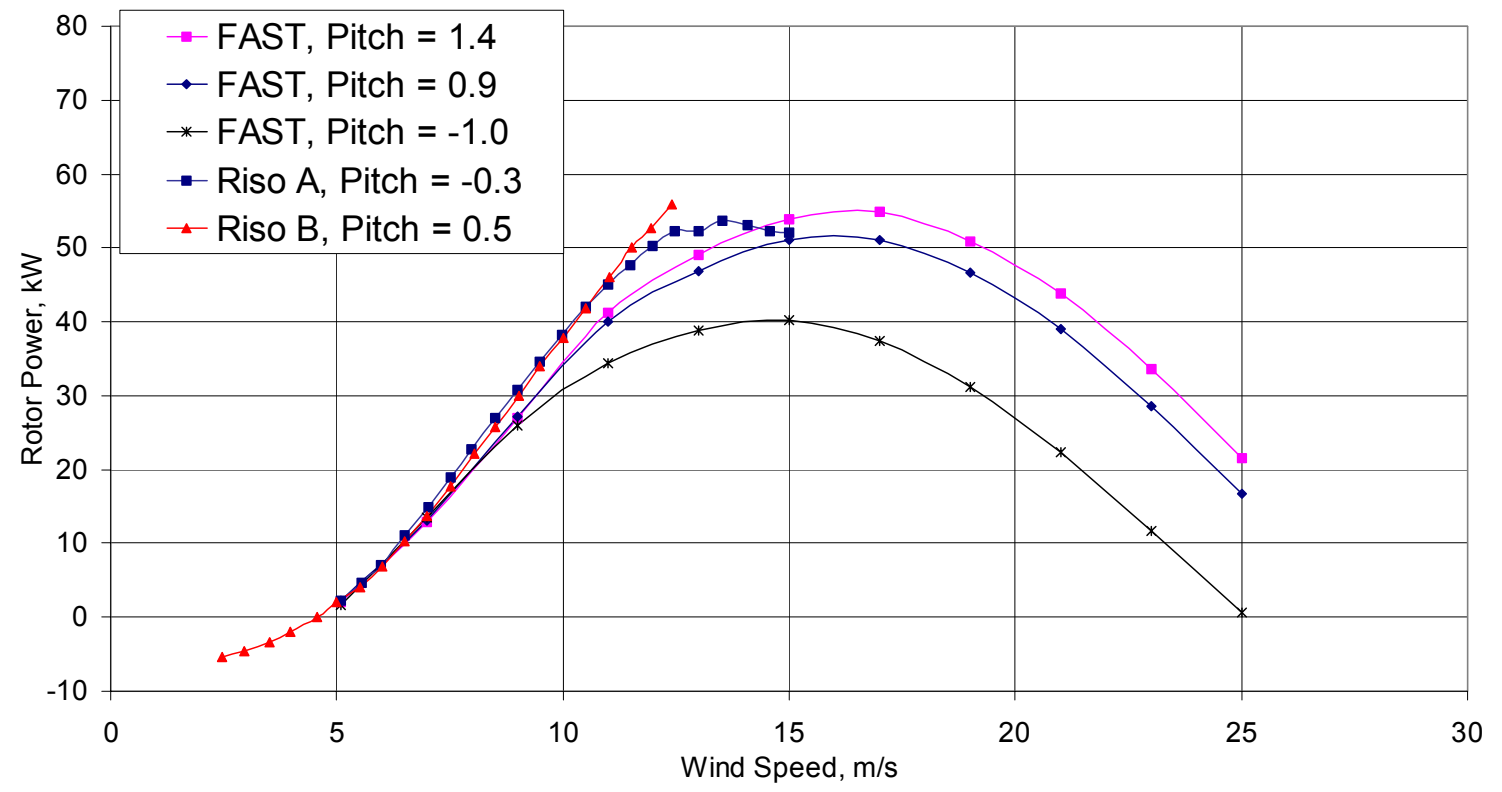

Figure 13. Comparison of FAST predictions with Risø test results. 


\section{Results of Loads Tests}

\section{Introduction}

Three laboratories participated in the mechanical loads portion of the round-robin program: Risø, CRES, and the NREL. Unfortunately, a combination of turbine and data acquisition troubles prevented CRES from completing its measurement campaign. The Risø and NREL tests provide contrasts in test turbine setup, mechanical loads measurement strategies, and test sites.

As described earlier in this report, the Risø and NREL test turbine setups are substantially different as a result of their respective test sites. The Risø test site is a typical northern European test site located at sea level and operating on a $50-\mathrm{Hz}$ power grid while the NREL turbine operates on a $60-\mathrm{Hz}$ grid and is located at an elevation of approximately $1850 \mathrm{~m}$. Table 1 highlights the main differences between the two turbine setups.

\section{Measured Parameters}

When this test effort began, the IEC 61400-13 standard had not yet been published, so there were no definitive channel maps provided to the participants. However, Table 2 shows the lists of channels for each measurement campaign agree quite well with no major discrepancies. The main differences between the two tests centered on the location of the various sensors. In particular, the loads measurement channels are all measured using strain gages, but the locations (provided in Table 3) of those gages vary significantly, making it difficult to compare those channels directly.

\section{Data Acquisition}

The Risø data acquisition system sampled all of the data at $32 \mathrm{~Hz}$. The wind speed signals were transmitted as pulses while the rest of the signals were amplified and transmitted at \pm 5 volts dc. The rotating system signals were sampled using a telemetry system mounted at the rotor hub, and they were transmitted as PCM data to the main data acquisition PC. Before entering the measurement computer, the signals passed through terminal boxes, lightning protection filters, and anti-aliasing filters. Data was processed in real time with only a few of the data sets retained, while the rest were deleted to save hard disk space.

The NREL Advanced Data Acquisition System (ADAS) sampled all channels at $160 \mathrm{~Hz}$ with $40-\mathrm{Hz}$ anti-aliasing filters on all loads channels. The data was then decimated to $40 \mathrm{~Hz}$ in the host computer. The rotor package consisted of a single, eight-channel data acquisition module (DAM) and its power supply attached to the hub, receiving power and communications via a four-channel slip ring that replaced the turbine's original rotary power transformer. All data acquired was stored on the host computer in tab-delaminated ASCII format.

\section{Calibration}

The Risø sensors and transmission lines were calibrated separately. The transmission line calibrations included: cables, lightning protection filters, low-pass filter-amplifiers, and the A/D board with DAQ data acquisition software. These lines were calibrated using a line calibrator 
that provided voltages ranging from $-4.0 \mathrm{~V}$ to $+4.0 \mathrm{~V}$. The anemometers were calibrated with a frequency calibration source with frequencies from 0 to $40 \mathrm{~Hz}$.

The Risø cup anemometers were calibrated in the DMI wind tunnel and showed deviations well within the requirements (all measured data points within $\pm 0.1 \mathrm{~m} / \mathrm{s}$ in the range from $4 \mathrm{~m} / \mathrm{s}$ to $10 \mathrm{~m} / \mathrm{s}$ and $\pm 1 \%$ from $10 \mathrm{~m} / \mathrm{s}$ when compared to the reference anemometer).

The Risø strain gages were calibrated by applying known, external loads to the blades in the edgewise and flapwise directions. The tower forces were calibrated by means of calculating the strain for uniaxial compression on the adapter (on which strain gages were mounted). The zero points for the rotor and main shaft loads were found by rotating the rotor around $360^{\circ}$ during low winds. The dead weights of the blades during slow rotations act as a constant zero indicator of the gravity moment upon the strain gage output.

NREL followed a similar procedure for calibration of the measurement chains for the nonload sensors. As for the load channels, end-to-end calibrations were performed on the blade \#1 flap bending, blade \#1 edge bending, blade \#2 flap bending, blade \#2 edge bending, low-speed shaft about the $0^{0}$ axis, low-speed shaft about the $90^{\circ}$ axis, main shaft torsion, tower north-to-south bending, and tower east-to-west bending. For the blade and low-speed shaft gages, a known load was applied near the blade tip and the blade was pulled downwind away from the tower for flap and shaft bending, while blade edge and shaft torsion were calibrated by positioning the test blade horizontal and applying a downward force at the tip. For the tower gages, a known load was applied to the tower-top at the yaw bearing, parallel to the ground. Each test was performed by trained NREL personnel and photographically documented.

Blade flap and edge and shaft slow rotations were taken throughout the test to ensure proper gage zeros. The methodology was similar to Risø's except that the turbines motoring function was used; the turbine was motored up to near rated rpm and then allowed to slowly decrease until near idle. The tower base gages were zeroed much less frequently, because the procedure was much more difficult. A rope had to be attached from one of the blades to the ground and used to yaw the turbine $360^{\circ}$ on low wind days. 
Table 2. Loads Measurement Channels

\begin{tabular}{|c|c|c|}
\hline Parameter & Risø & NREL \\
\hline $\begin{array}{l}\text { Primary Wind Speed at Hub Height } \\
25.6\end{array}$ & Risø Cup anemometer, P2445b & $\begin{array}{l}\text { Met One, } 010 \mathrm{C} \text { w/aluminum } \\
\text { vane }\end{array}$ \\
\hline $\begin{array}{l}\text { Secondary Wind Speed at Hub } \\
\text { Height } 25.6\end{array}$ & NA & $\begin{array}{l}\text { Met One, } 010 \mathrm{C} \text { w/aluminum } \\
\text { vane }\end{array}$ \\
\hline Secondary Wind Speed at $23.5 \mathrm{~m}$. & Risø Cup anemometer, P1987b & NA \\
\hline Wind Direction, Sin at $23 \mathrm{~m}$. & Risø wind vane P202c & NA \\
\hline Wind Direction, Cos at $23 \mathrm{~m}$. & & NA \\
\hline Wind Direction at $23 \mathrm{~m}$. & & $\begin{array}{l}\text { Met One, 020C w/aluminum } \\
\text { vane }\end{array}$ \\
\hline Temperature. & Pt100 B sensor at $23 \mathrm{~m} \mathrm{agl}$ & $\begin{array}{l}\text { Met One, T-200 RTD at } 22 \mathrm{~m} \\
\text { agl }\end{array}$ \\
\hline Atmospheric Pressure & PTB100B Vaisala at $15 \mathrm{~m} \mathrm{agl}$ & PTB101B Vaisala at $22 \mathrm{~m} \mathrm{agl}$ \\
\hline Rain & F23388a Vaisala & NA \\
\hline Yaw Direction, Sin & P2420 direction transmitter & NA \\
\hline Yaw Direction, Cos & “" & NA \\
\hline Yaw Direction & “ & CCC, HSTDCC-PB16S \\
\hline Rotor Speed & Namur inductive sensor & Red Lion, LMPCC \\
\hline Rotor Status & Isolation amplifier/controller & NA \\
\hline Rotor Position (azimuth) & & Red Lion, LMPCC \\
\hline Nacelle Anemometer & Risø Cup anemometer, P1110b & NA \\
\hline Axial force tower pole \#1 & $\begin{array}{l}\text { Strain Gage, CEA-06-167UV- } \\
350\end{array}$ & $\begin{array}{l}\text { Strain Gage, LWK-06- } \\
\text { W250B-350 }\end{array}$ \\
\hline Axial force tower pole $\# 2$ & $\begin{array}{l}\text { Strain Gage, CEA-06-167UV- } \\
350\end{array}$ & $\begin{array}{l}\text { Strain Gage, LWK-06- } \\
\text { W250B-350 }\end{array}$ \\
\hline Axial force tower pole \#3 & $\begin{array}{l}\text { Strain Gage, CEA-06-167UV- } \\
350\end{array}$ & $\begin{array}{l}\text { Strain Gage, LWK-06- } \\
\text { W250B-350 }\end{array}$ \\
\hline Flap Bending Blade \#1 & $\begin{array}{l}\text { Strain Gage, CEA-06-250UT- } \\
350\end{array}$ & $\begin{array}{l}\text { Strain Gage, LWK-06- } \\
\text { W250B-350 }\end{array}$ \\
\hline Flap Bending Blade \#2 & $\begin{array}{l}\text { Strain Gage, CEA-06-250UT- } \\
350\end{array}$ & $\begin{array}{l}\text { Strain Gage, LWK-06- } \\
\text { W250B-350 }\end{array}$ \\
\hline Flap Bending Blade \#3 & $\begin{array}{l}\text { Strain Gage, CEA-06-250UT- } \\
350\end{array}$ & $\begin{array}{l}\text { Strain Gage, LWK-06- } \\
\text { W250B-350 }\end{array}$ \\
\hline Edge Bending Blade \#1 & $\begin{array}{l}\text { Strain Gage, CEA-06-250UT- } \\
350\end{array}$ & $\begin{array}{l}\text { Strain Gage, LWK-06- } \\
\text { W250B-350 }\end{array}$ \\
\hline Edge Bending Blade \#2 & $\begin{array}{l}\text { Strain Gage, CEA-06-250UT- } \\
350\end{array}$ & $\begin{array}{l}\text { Strain Gage, LWK-06- } \\
\text { W250B-350 }\end{array}$ \\
\hline Edge Bending Blade \#3 & $\begin{array}{l}\text { Strain Gage, CEA-06-250UT- } \\
350\end{array}$ & NA \\
\hline Shaft Bending Moment X & $\begin{array}{l}\text { Strain Gage, HBM type } 6 / 350 \\
\text { DK } 21 \mathrm{~K}\end{array}$ & $\begin{array}{l}\text { Strain Gage, LWK-06- } \\
\text { W250B-350 }\end{array}$ \\
\hline Shaft Bending Moment Y & $\begin{array}{l}\text { Strain Gage, HBM type } 6 / 350 \\
\text { DK } 21 \mathrm{~K}\end{array}$ & $\begin{array}{l}\text { Strain Gage, LWK-06- } \\
\text { W250B-350 }\end{array}$ \\
\hline Shaft Torque & $\begin{array}{l}\text { Strain Gage, CEA-06-167UV- } \\
350\end{array}$ & $\begin{array}{l}\text { Strain Gage, CEA-06- } \\
187 \mathrm{UV}-350\end{array}$ \\
\hline Tilt Bending Moment & Calculated Channel & Calculated Channel \\
\hline
\end{tabular}




\begin{tabular}{|l|l|l|}
\hline Yaw Bending Moment & Calculated Channel & Calculated Channel \\
\hline Yaw Rate & Calculated Channel & NA \\
\hline Electrical Power & Current Transformer, 450/1A & OSI GWV5-008EY05 \\
\hline Status Generator $50 \mathrm{~kW}$ & Isolation Amplifier/controller & NA \\
\hline Status Blade Tip & Isolation Amplifier/controller & NA \\
\hline
\end{tabular}

Table 3. Location Loads Measurement Channels

\begin{tabular}{|l|l|l|}
\hline Parameter & Risø & NREL \\
\hline Flap Bending Blade \#1 & Radius $\mathrm{R}=0.7 \mathrm{~m}$. & Radius $\mathrm{R}=0.1651 \mathrm{~m}$. \\
\hline Flap Bending Blade \#2 & Radius $\mathrm{R}=0.7 \mathrm{~m}$. & Radius $\mathrm{R}=0.1651 \mathrm{~m}$. \\
\hline Flap Bending Blade \#3 & Radius $\mathrm{R}=0.7 \mathrm{~m}$. & Radius $\mathrm{R}=0.1651 \mathrm{~m}$. \\
\hline Edge Bending Blade \#1 & Radius $\mathrm{R}=0.7 \mathrm{~m}$. & Radius $\mathrm{R}=0.1651 \mathrm{~m}$. \\
\hline Edge Bending Blade $\# 2$ & Radius $\mathrm{R}=0.7 \mathrm{~m}$. & Radius $\mathrm{R}=0.1651 \mathrm{~m}$. \\
\hline Edge Bending Blade $\# 3$ & Radius $\mathrm{R}=0.7 \mathrm{~m}$. & Radius $\mathrm{R}=0.1651 \mathrm{~m}$. \\
\hline Shaft Bending Moment $\mathrm{X}$ & $0.1 \mathrm{~m}$. Downwind of hub & $0.05 \mathrm{~m}$. Downwind of hub \\
\hline Shaft Bending Moment $\mathrm{Y}$ & $0.1 \mathrm{~m}$. Downwind of hub & $0.05 \mathrm{~m}$. Downwind of hub \\
\hline Shaft Torque & $0.1 \mathrm{~m}$. Downwind of hub & $0.05 \mathrm{~m}$. Downwind of hub \\
\hline Axial Force Tower Pole \#1 & $@$ Approximately $0.5 \mathrm{~m}$. height & $@, 1 \mathrm{~m}$. Height \\
\hline Axial Force Tower Pole \#2 & $@$ Approximately $0.5 \mathrm{~m}$. height & $@, 1 \mathrm{~m}$. Height \\
\hline Axial Force Tower Pole \#3 & $@$ Approximately $0.5 \mathrm{~m}$. height & $@ 1 \mathrm{~m}$. Height \\
\hline
\end{tabular}

\section{Results}

\section{Data Collected}

At the time of the round-robin load measurement campaigns, no approved standard existed. The 61400-13 draft had yet to be approved so no official recommendation for a capture matrix existed. Figure 14 shows the amount of normal power production data acquired by both Risø and NREL. This figure demonstrates both the differences in test site and test philosophy of the two laboratories. NREL collected 154 data sets while Risø collected 1173 . It is interesting to note that despite the disparity of the total amount of data collected, only the NREL test would meet the requirements of the current 61400-13 standard and only then for the "model-validation" capture matrix. 


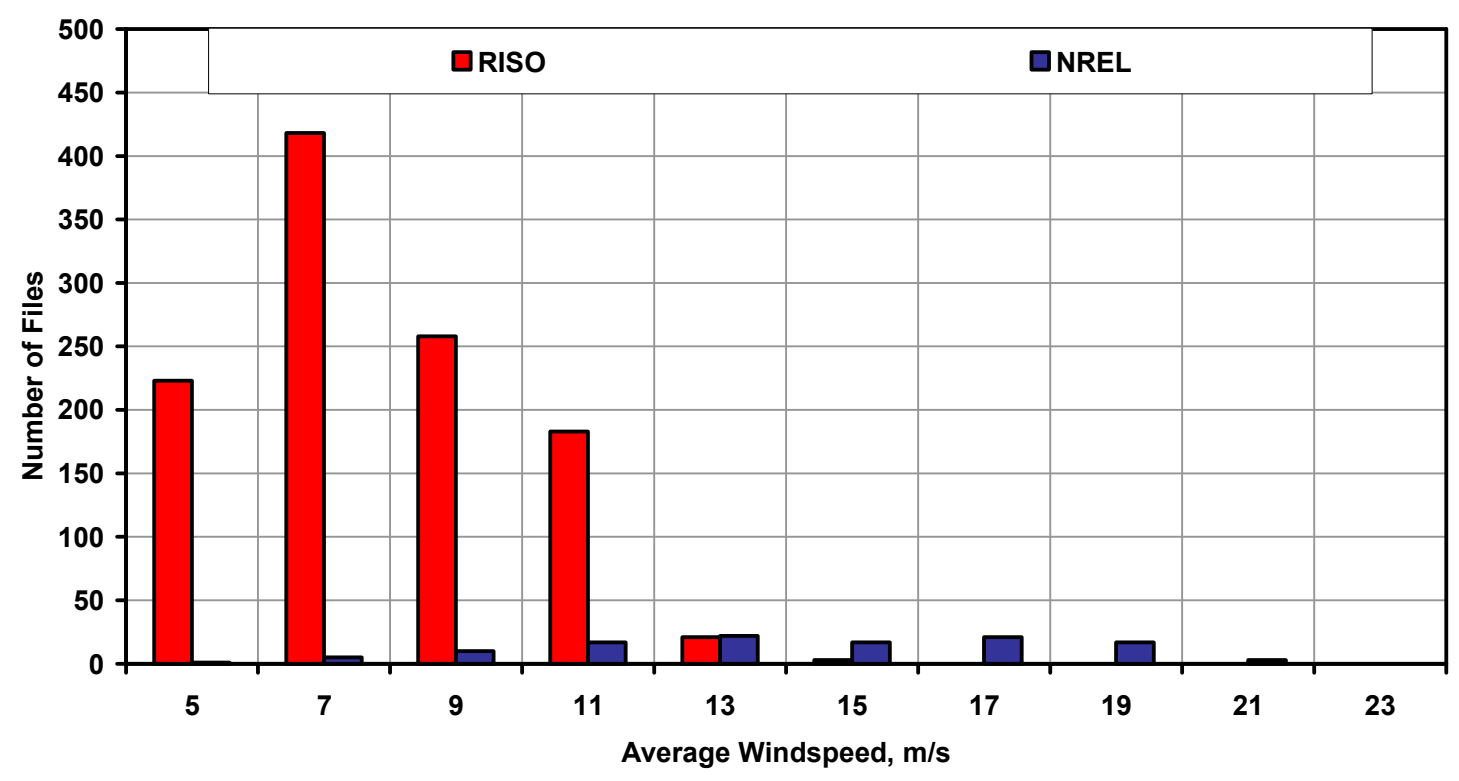

14. Comparison of Risø and NREL files acquired.

Figure

Figure 15 shows the scatter plot of turbulence intensity versus wind speed for the acquired 10minute data sets for the two tests. The Risø site can be characterized as a low turbulence site while the NREL site might be characterized as a high turbulence site. Also the NREL site has extreme winds with a peak 10-minute average wind of $22 \mathrm{~m} / \mathrm{s}$ while the Risø site has a maximum 10 -minute average of approximately $15 \mathrm{~m} / \mathrm{s}$. With increasing wind speed it appears as though the turbulence intensity at Risø approaches an average of approximately $10 \%$ while the NREL data indicates a value around $16 \%-18 \%$.

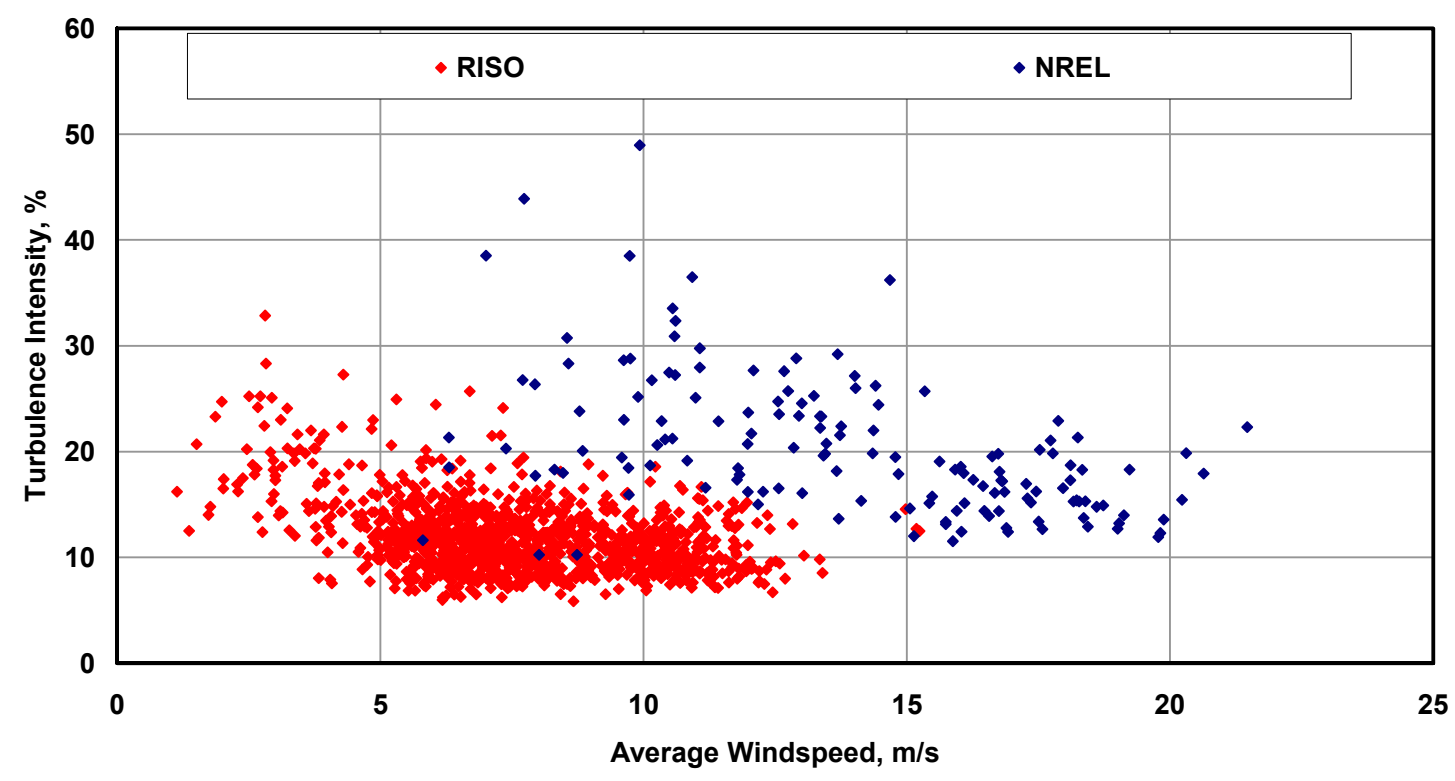

Figure 15. Comparison of Risø and NREL turbulence intensity. 


\section{Comparison of Raw Data}

Scatter plots found in Figure 16, Figure 17, Figure 18, and Figure 19 show uncorrected data from the two campaigns. They highlight the differences in turbine setup, site properties and instrumentation setup. For example, Figure 16 shows the electrical power for the two tests. First, we note that the Risø data shows quite a bit of negative power being generated by the turbine at winds below $5 \mathrm{~m} / \mathrm{s}$ when the turbine is motoring. The Risø peak power is much greater that the NREL peak, this discrepancy is a combination of the different pitch setting, rotor speed and air density.

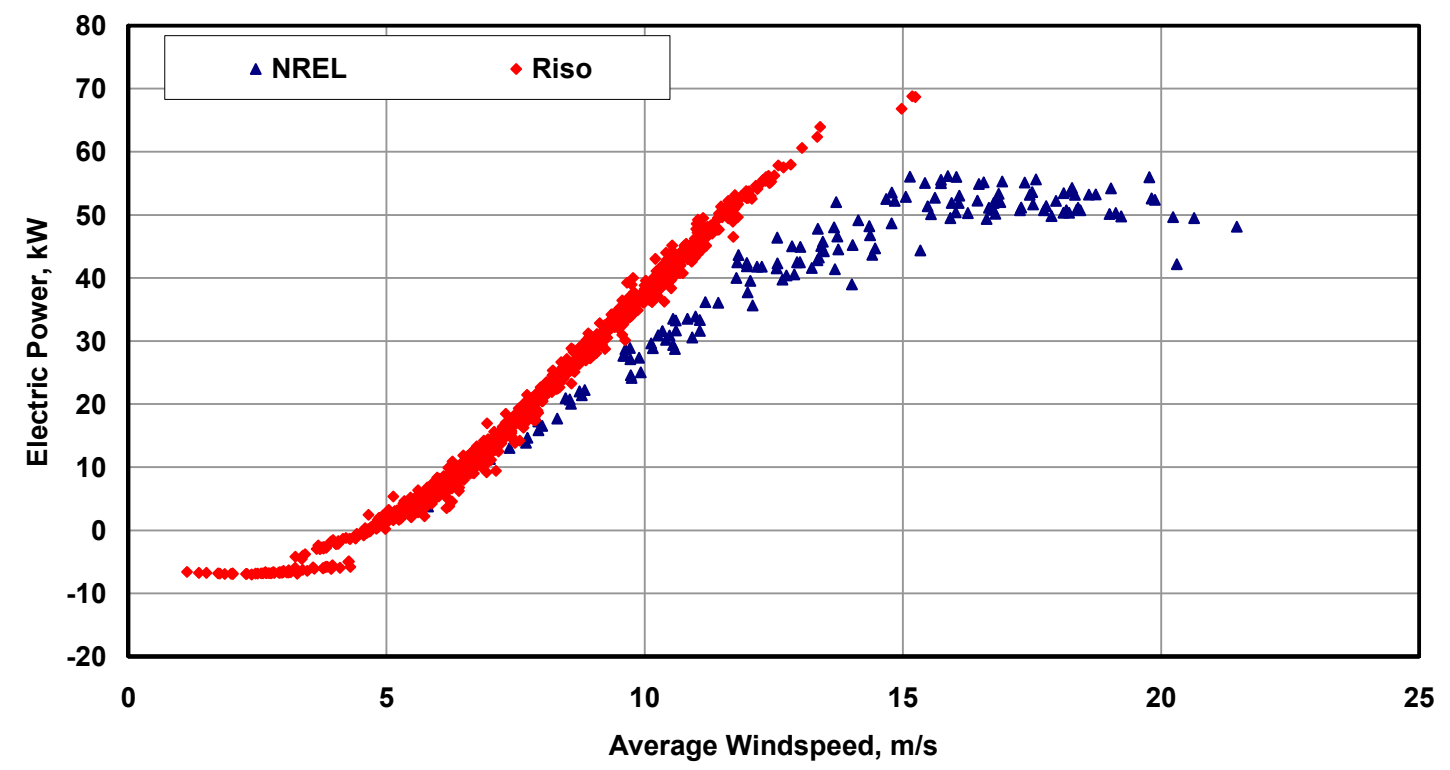

Figure 16. Comparison of Risø and NREL measured power curves. Based on loads data with no correction of wind speed for site effects or air density.

Figure 17 shows the 10-minute maximum, means, and minimums for flap bending on both turbines. There are many disparities to note. The AOC turbine has its blades coned $5^{\circ}$ downwind, so that when the turbine is spinning, the centrifugal force applies an upwind (negative) moment to the blade roots. The flap bending strain gages on the Risø turbine are farther outboard than the NREL ones, the centrifugal moment of the blades is therefore less than NREL's and can be seen at low wind speeds where the aerodynamic loads are less. In addition, the Risø runs at a slightly lower rpm than the NREL turbine, which increases this disparity. The aerodynamic moments are normally positive and tend to counteract the centrifugal moments as the wind speed increases. The higher air density at sea level causes the Risø moments to be greater than the NREL moments as the wind speeds increase. Finally, the effect of the higher NREL turbulence intensity can be seen by the greater minimum/maximum ranges. 


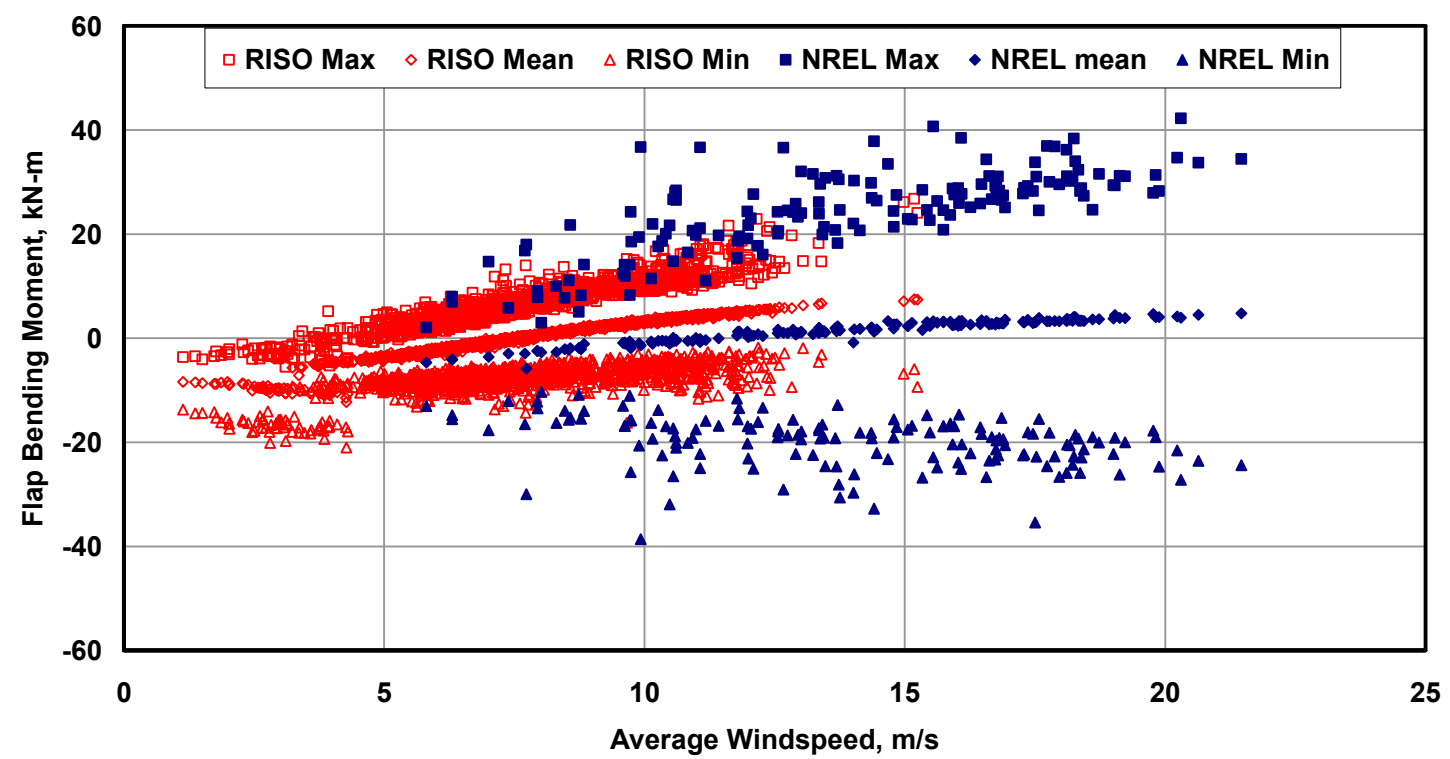

Figure 17. Comparison of Risø and NREL measured flap-bending moments.

The edge bending moments are not subject to the centrifugal loads, and therefore, the mean moments at low-wind speeds tend toward zero. The minimum/maximum ranges for both sets of data are dominated by the gravity loads; therefore, they are quite similar, especially at lower wind speeds. As the wind speeds increase, however, the NREL data again shows greater ranges because of higher turbulence and possibly greater vertical wind shear.

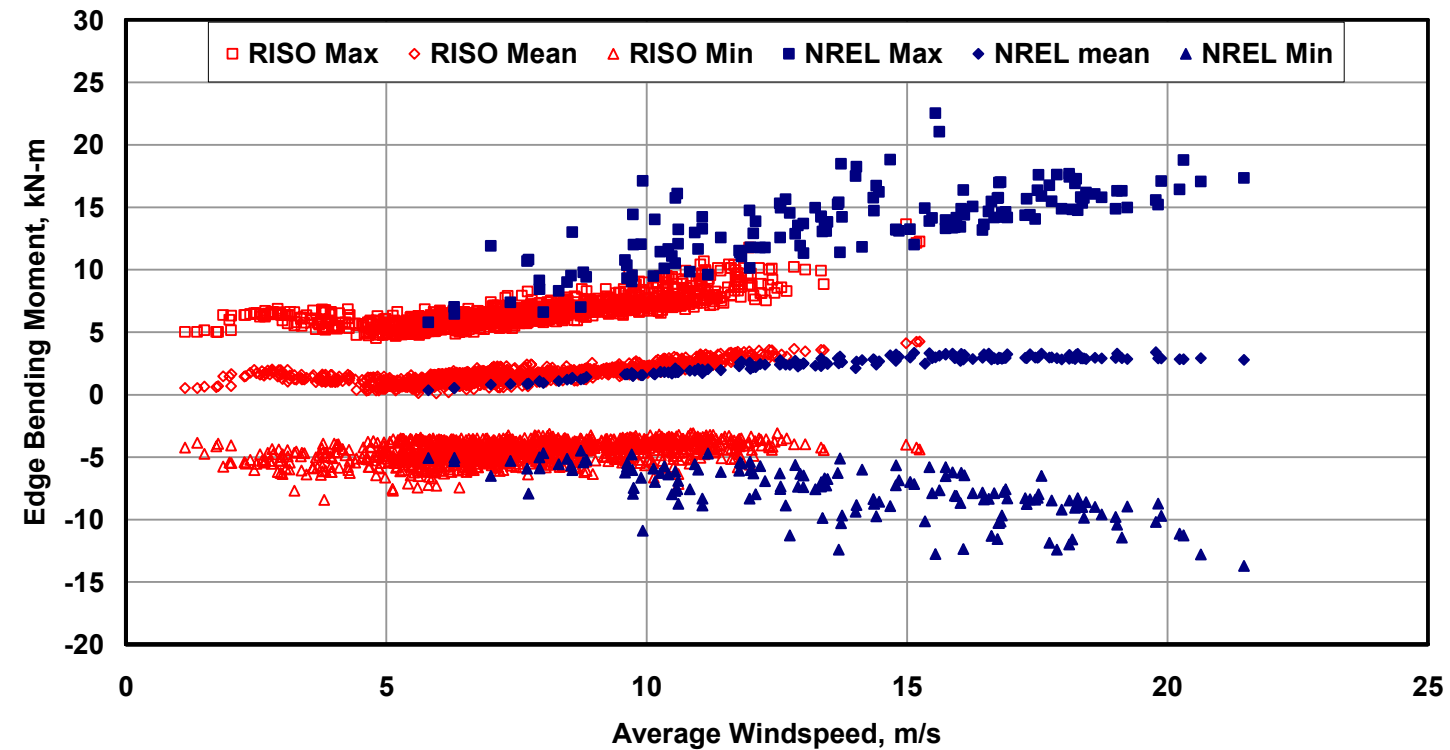

Figure 18. Comparison of Risø and NREL measured edge-bending moments.

The low-speed shaft bending shown in Figure 19 follows the same trends as the edge bending moments. The means for the shaft bending are zero and are dominated in low wind speeds by the gravity moment $s$ of the hub and blades. Once again, the NREL data shows greater 
minimum/maximum ranges and are probably the result of higher turbulence intensity and increased gyroscopic moments caused by higher yaw rates.

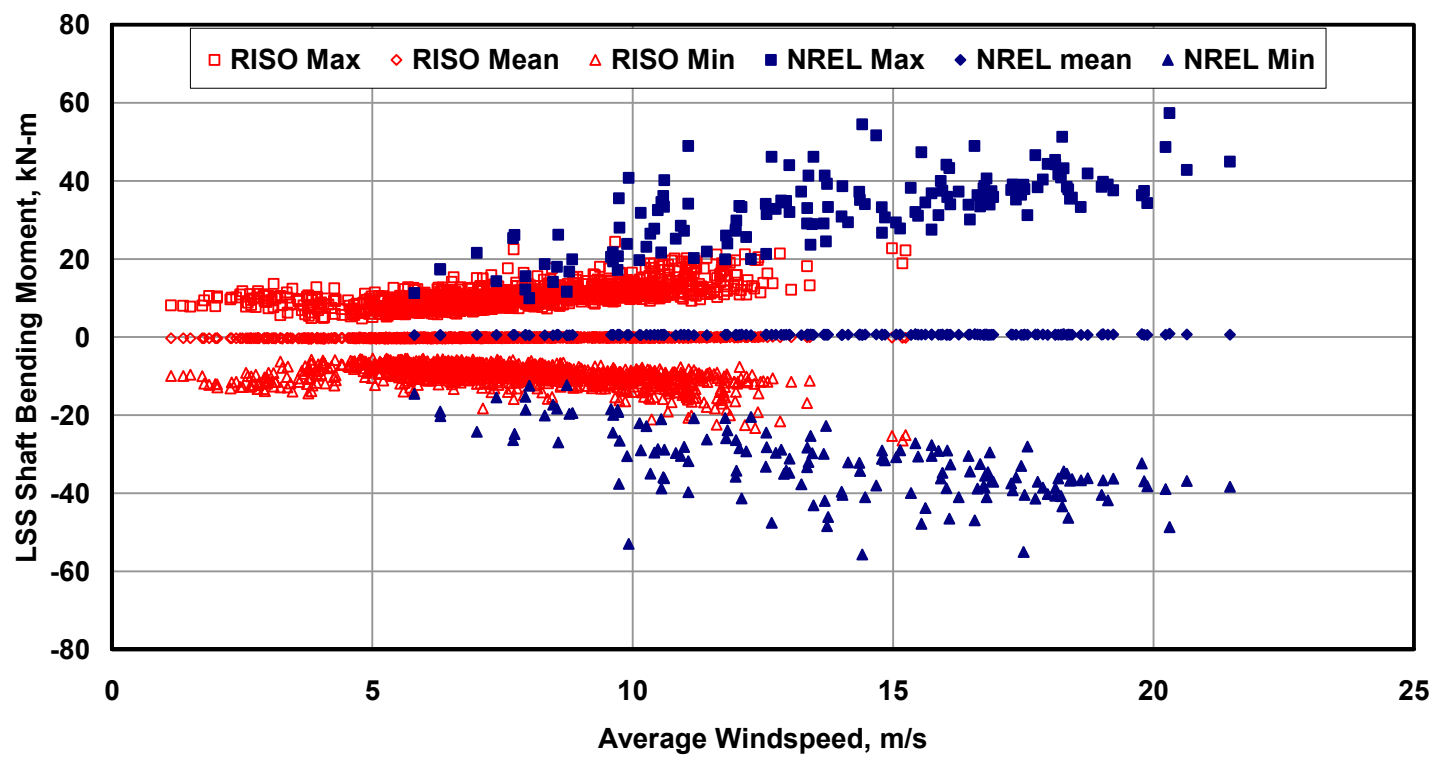

Figure 19. Comparison of Risø and NREL low-speed shaft bending moments.

\section{Use of Aeroelastic Simulation}

The deviations in pitch setting, air density, strain-gage location, and rotor rpm made direct comparison of the two loads tests impossible. In an effort to correctly account for these differences in turbine setting parameters, site differences, and sensor locations, NREL created a FAST (Fatigue, Aerodynamic, Structural, Turbulence) aeroelastic model of the AOC 15/50 to compare results from the two tests. The model was tuned to match the AOC power and flap bending curves by adjusting the 2 -dimensional airfoil data via an optimization routine. The aeroelastic turbine model was then run using wind inflow based on the turbulence intensity and mean wind speed statistics of the NREL test data. Figure 20 and Figure 21 show that the model behaves in a very similar manner to the test data, with a slight under prediction of peak power and slight over prediction of absolute values for maximum and minimum flap bending moments at higher wind speeds. These differences may be attributed to a slight over estimation of the turbine yaw rates that lead to higher flap bending ranges and slightly poorer power performance.

Equivalent loads are used as a metric for measuring the relative rates of fatigue accumulation for various loads. Figure 22 shows a comparison of the FAST blade flap equivalent loads with the test data. The model predictions and test data show good correlation with the model predicting slightly higher fatigue loads, probably because not enough yaw damping leading to greater gyroscopic fatigue loads in the model. 


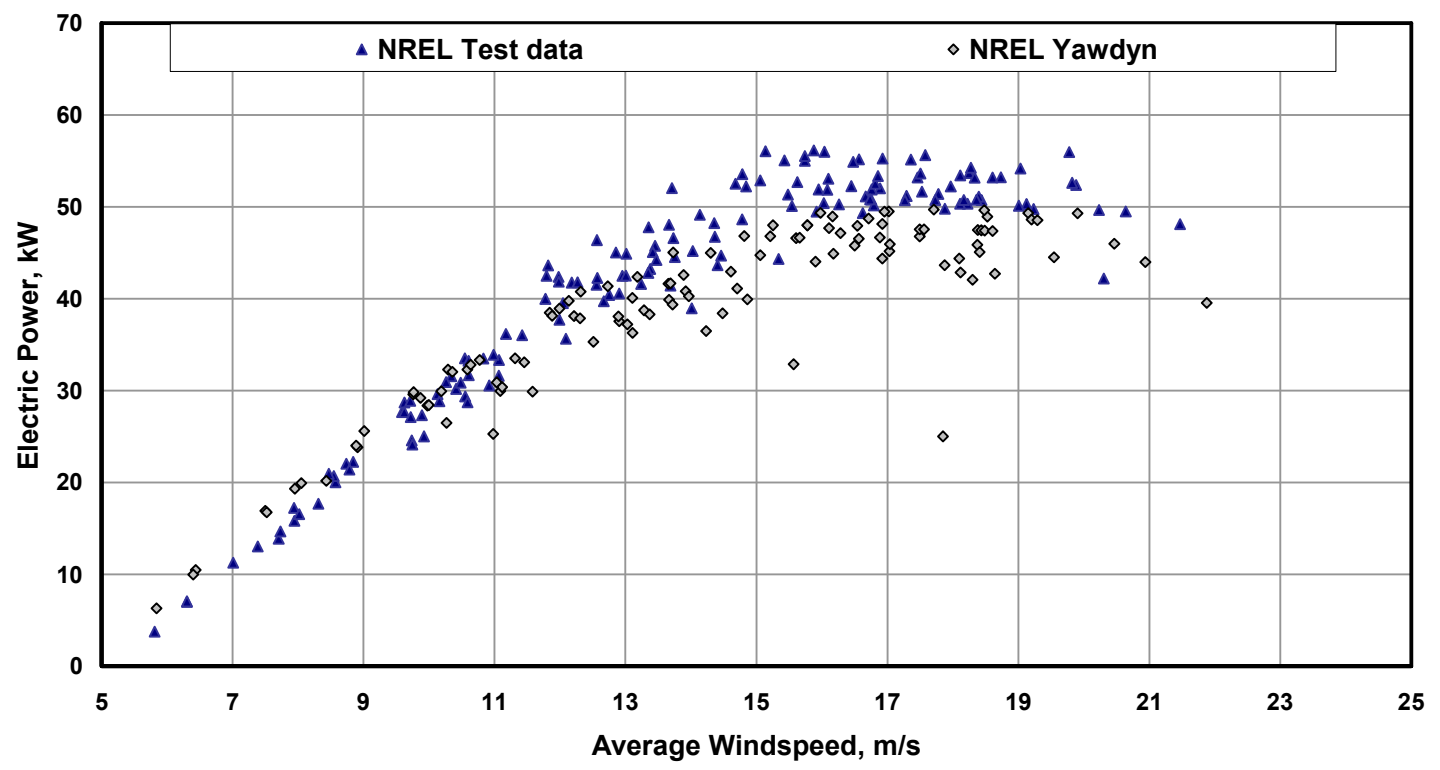

Figure 20. Comparison of FAST predictions with NREL power curves.

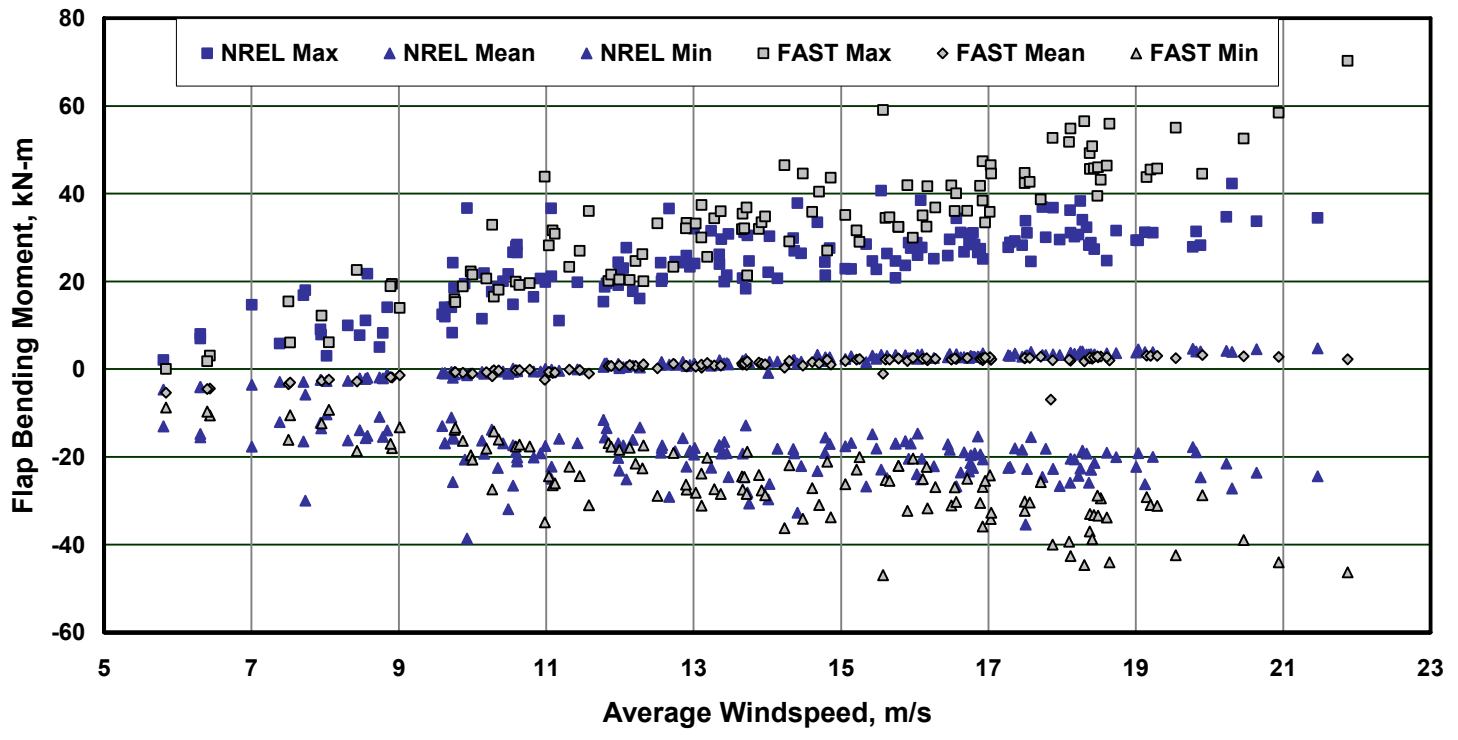

Figure 21. Comparison of FAST predictions with NREL flap bending moments. 


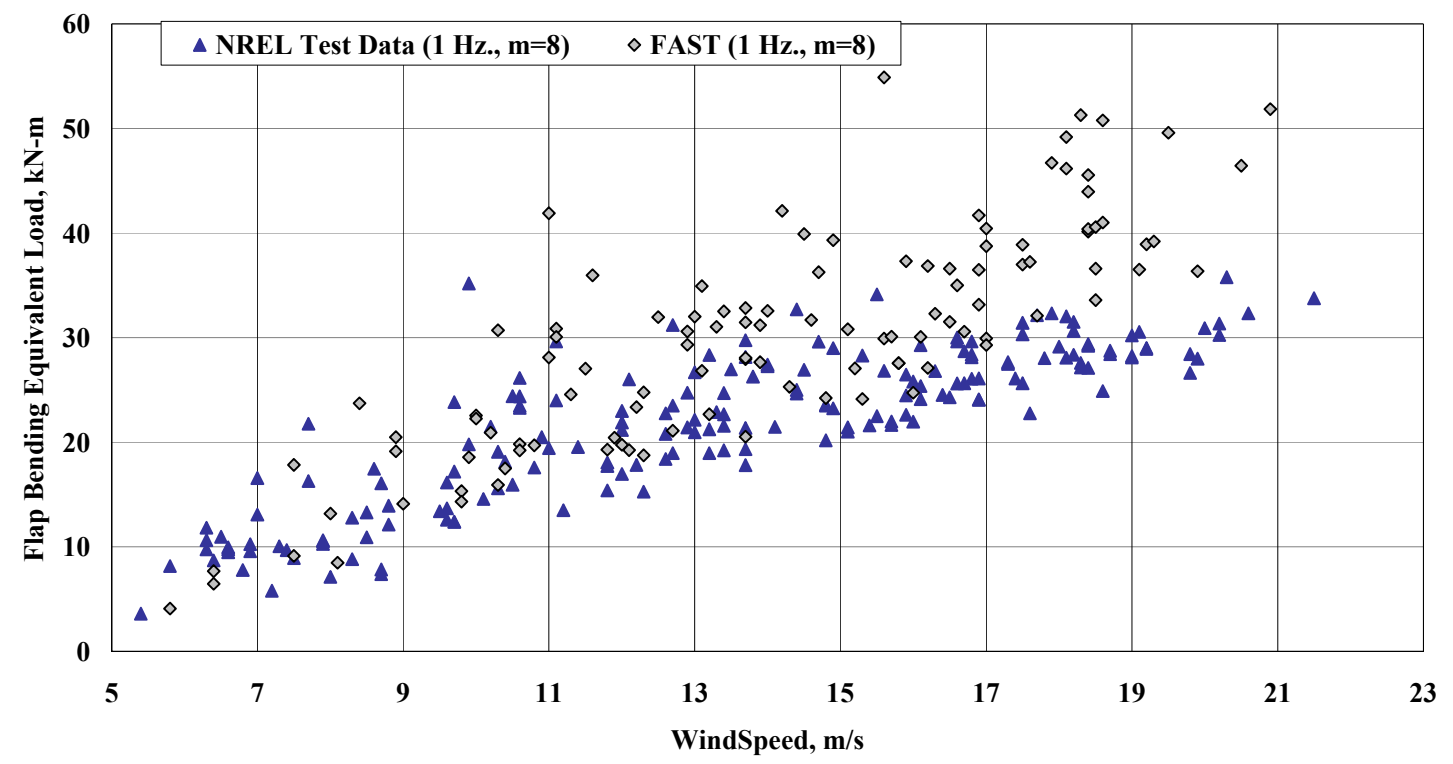

Figure 22. Comparison of FAST predictions with NREL flap equivalent loads.

\section{Predict Risø Data}

Once confidence with the FAST model was achieved with the NREL test data, the pitch setting, the rotor rpm, the blade root strain-gage locations, and the air density were adjusted to match the Risø test turbine configuration. Without modifying the airfoil data, the mean wind speed and turbulence intensity statistics were used to run simulations that would predict the performance of the actual test turbine. This section compares the results of the FAST model with the Risø test data.

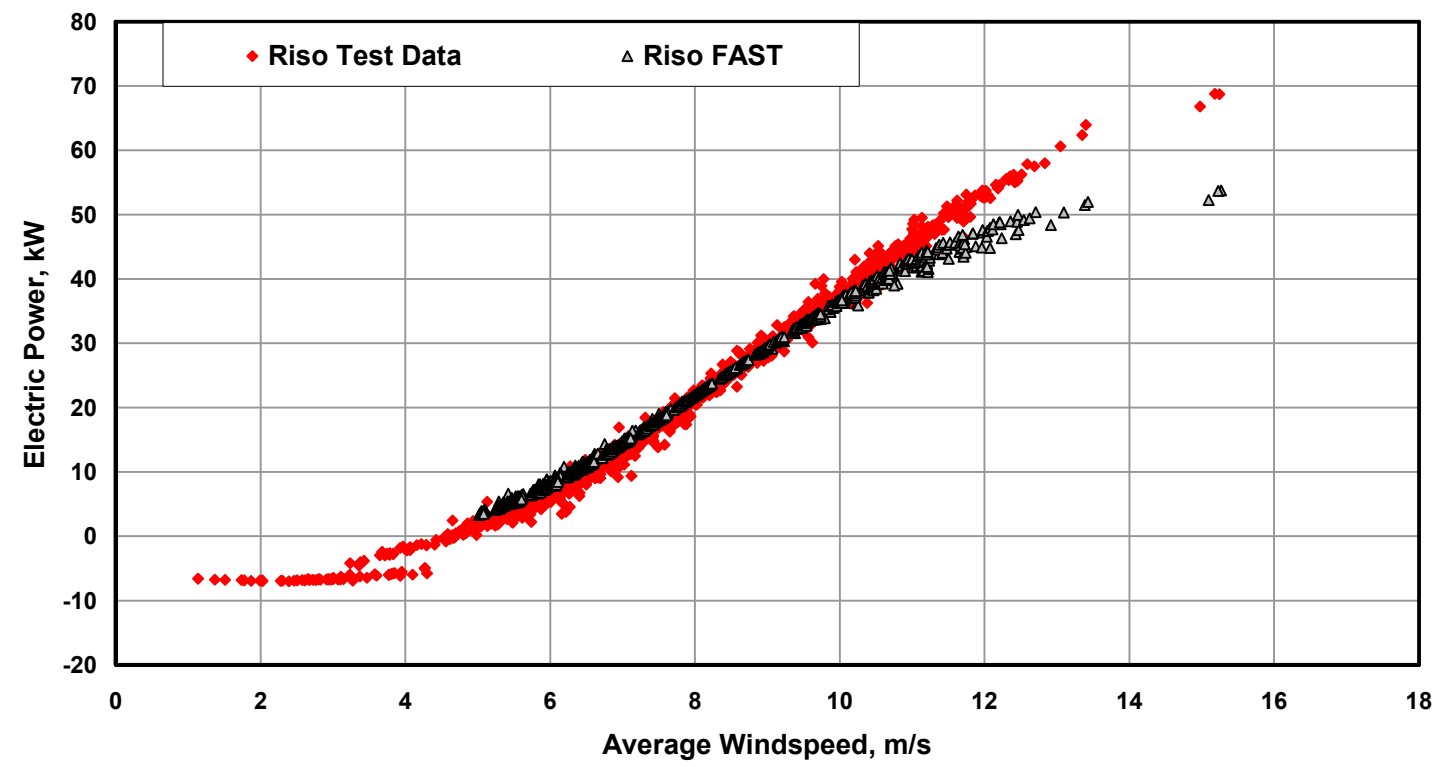

Figure 23. Comparison of FAST predictions with Risø measured power curves. 


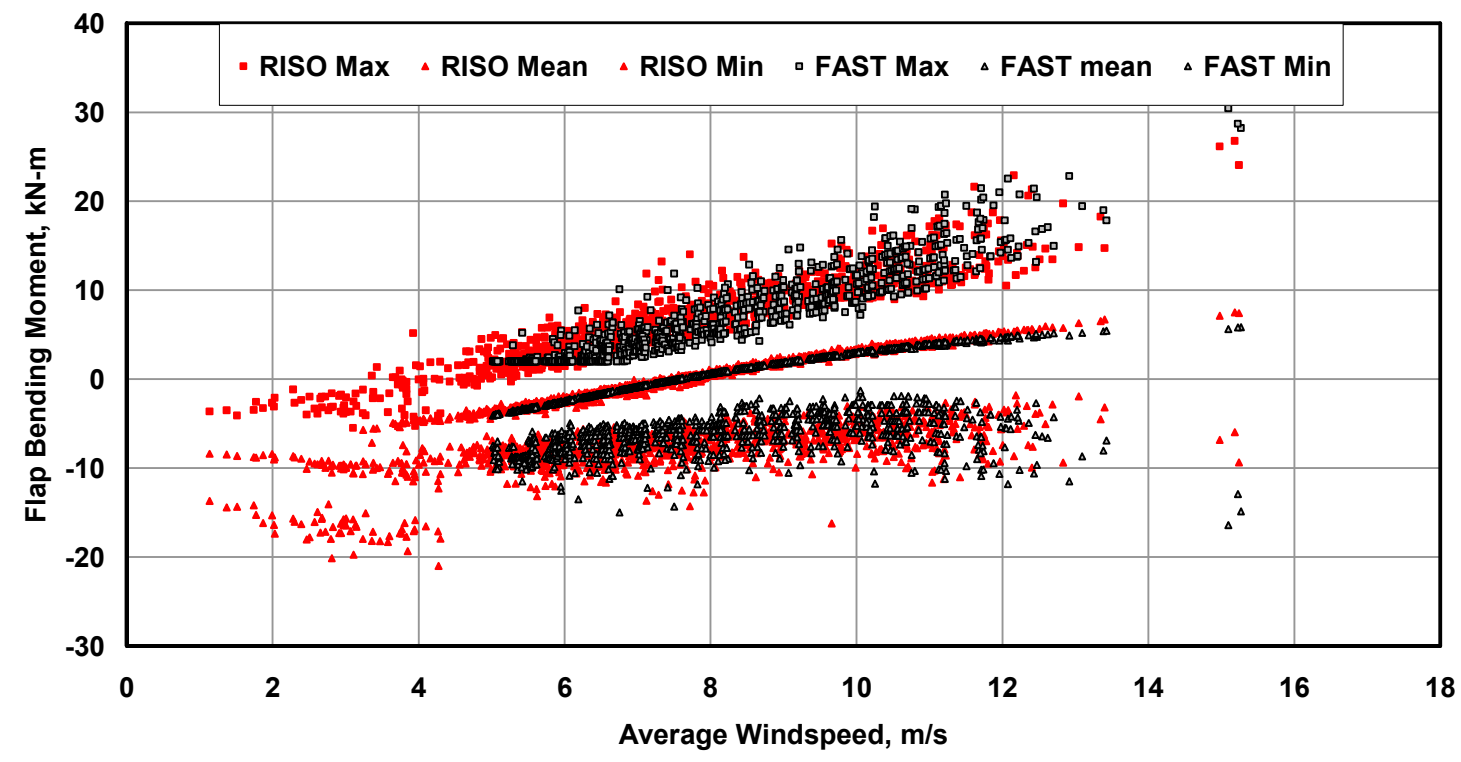

Figure 24. Comparison of FAST predictions with Risø measured flap bending moments.

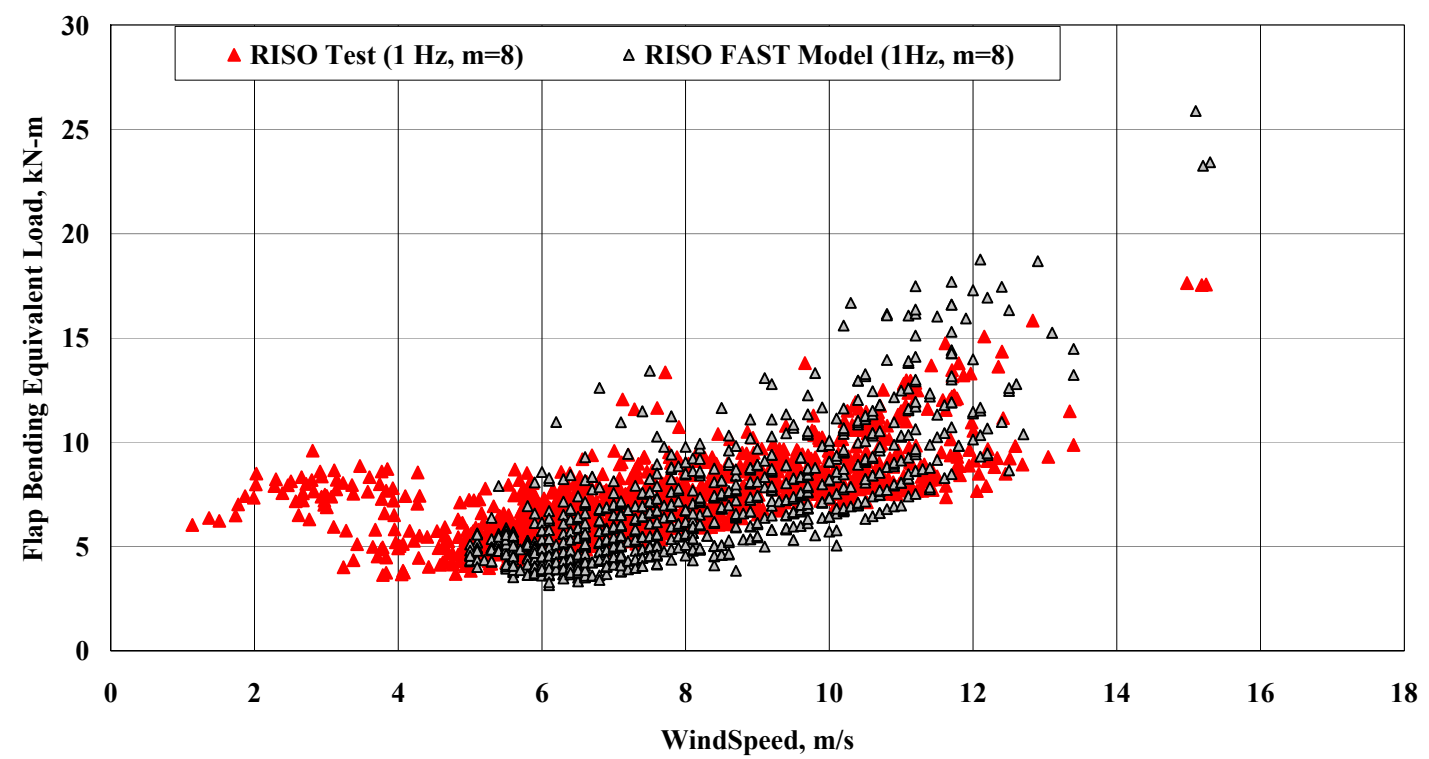

Figure 25. Comparison of FAST predictions with Risø measured flap equivalent loads.

\section{Conclusions}

The following are the primary conclusions from the Wind Turbine Round-Robin Testing Task:

1. After wind tunnel calibrations, common anemometers demonstrate differences in readings obtained in complex terrain up to $2 \%$.

2. The response of common anemometers to tilt angle varies from -4 to $+4 \%$ depending upon anemometer type and whether the anemometer is angled toward the wind or away from the wind. 
3. IEC 61400-12 requirements for rejection of test data may lead to large variations in test results depending on how the testing organization defines "turbine availability." In some cases, data may be rejected because the turbine is off-line in what is otherwise normal operation. The new draft of IEC 61400-12 specifies that off-line data shall NOT be rejected when the turbine is otherwise operating normally.

4. Test results can be strongly influenced by other interpretations of IEC 61400-12, wherein conditions such as up-wind operation, tip brake deployment or non-operation because of brake cooling are interpreted as "normal" or "faulted" by the testing organization.

5. Measurement of blade pitch settings is more difficult and uncertain than previously assumed by participants.

6. Differences in turbine setup and test site conditions prevent direct comparison of loads results.

7. Models can be tuned only if data are available from a sufficient wind speed range to define alpha from the linear region through stall. 


\section{References}

Paulsen, U.S. (1999). "Wind Turbine Test: AOC 15/50, 50-Hz Power Curve Measurements IEC (sic) Annex 16,” Risø-I-1310(EN), Risø National Laboratory, Roskilde, Denmark.

Paulsen, U.S. (2001). "Wind Turbine Test: AOC 15/50, 50-Hz Load Measurements IEC (sic) Annex 16," Risø-I-1651(EN), Risø National Laboratory, Roskilde, Denmark.

Brothers, C.; Rong, J. (2001). “AOC 15/50 Wind Turbine Performance Test Report IEA Annex 16," Atlantic Wind Test Site Inc. North Cape, PE, Canada.

Papadopoulos, K.H.; Morfiadakis, E.; Stefanatos, N.C.; Link, H.; Paulsen, U.S. (1999) "Performance assessment of cup anemometers" Proceedings of the 1999 European Wind Energy Conference, No PB9, European Wind Energy Association, Brussels, Belgium.

Jacobson, R. (2000). "Wind Turbine Generator System Power Performance Test Report for the Atlantic Orient 15/50 Wind Turbine" National Renewable Energy Laboratory, Golden, CO, U.S.A.

Stefanatos N.C., E.E. Morfiadakis, K.H. Papadopoulos (1997), 'CRES experience in cup anemometer calibration using MEASNET procedure', Proceedings EWEC97, 413-417, Ed. R.Watson.

Wind Turbine Generator Systems - Part 12: Wind Turbine: Power Performance Testing, IEC 6140012,First edition Feb 1998, International Electrotechnical Commission, Geneva, Switzerland, 1998. 


\section{REPORT DOCUMENTATION PAGE}

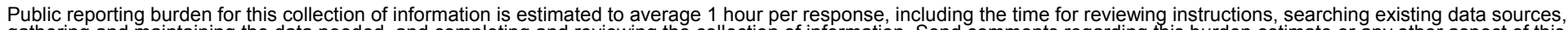

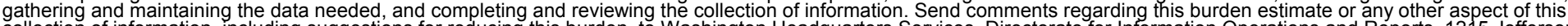

( Davis Highway, Suite 1204, Arlington, VA 22202-4302, and to the Office of Management and Budget, Paperwork Reduction Project (0704-0188), Washington, DC 20503.

\begin{tabular}{|l|l|l|}
\hline 1. AGENCY USE ONLY (Leave blank) & $\begin{array}{l}\text { 2. REPORT DATE } \\
\text { May } 2004\end{array}$ & $\begin{array}{l}\text { 3. REPORT TYPE AND DATES COVERED } \\
\text { Technical Report }\end{array}$ \\
\hline
\end{tabular}

4. TITLE AND SUBTITLE

International Energy Agency Wind Turbine Round-Robin Test Task

6. $\operatorname{AUTHOR}(\mathrm{S})$

H.F. Link and R. Santos

7. PERFORMING ORGANIZATION NAME(S) AND ADDRESS(ES)

National Renewable Energy Laboratory

1617 Cole Blvd.

Golden, CO 80401-3393

9. SPONSORING/MONITORING AGENCY NAME(S) AND ADDRESS(ES)
5. FUNDING NUMBERS

WER43601

8. PERFORMING ORGANIZATION REPORT NUMBER NREL/TP-500-36238

10. SPONSORING/MONITORING AGENCY REPORT NUMBER

11. SUPPLEMENTARY NOTES

12a. DISTRIBUTION/AVAILABILITY STATEMENT

National Technical Information Service

12b. DISTRIBUTION CODE

U.S. Department of Commerce

5285 Port Royal Road

Springfield, VA 22161

13. ABSTRACT (Maximum 200 words)

This report describes the work and the results of Annex XVI, Wind Turbine Round-Robin Test Task, performed under the auspices of the International Energy Agency's (IEA's) Agreement for Cooperation in the Research and Development of Wind Turbine Systems (IEA R\&D WTS). The objectives of Annex XVI were to validate wind turbine testing procedures, analyze and resolve sources of discrepancies, and to improve the testing methods and procedures. All participating laboratories tested similar wind turbines at their own facilities, using comparable test instrumentation and data acquisition equipment.

14. SUBJECT TERMS

wind energy; wind turbine; Annex XVI; International Energy Agency; Round-Robin

15. NUMBER OF PAGES

16. PRICE CODE

17. SECURITY CLASSIFICATION OF REPORT Unclassified
18. SECURITY CLASSIFICATION OF THIS PAGE Unclassified
19. SECURITY CLASSIFICATION OF ABSTRACT Unclassified
20. LIMITATION OF ABSTRACT

UL 